\title{
TIPOLOGÍAS DE CONSUMO DE AGUA EN ABASTECIMIENTOS URBANO-TURÍSTICOS DE LA COMUNIDAD VALENCIANA ${ }^{1}$
}

\author{
Antonio M. Rico Amorós \\ Instituto Universitario de Geografía \\ Universidad de Alicante.
}

\section{RESUMEN}

El análisis de las unidades de consumo de agua asociadas a las actividades turísticas resulta imprescindible para valorar la eficiencia ambiental y socioeconómica del modelo de desarrollo territorial urbano-turístico valenciano. Este trabajo analiza el gasto de agua urbano-turístico en las distintas formas de implantación territorial de estas actividades, especialmente en la modalidades de alojamiento hotelero y residencial, comparando la eficiencia de la gestión del agua potable en modelos urbanos de baja densidad y de alta densidad (concentrados). Para dicho fin se ha recurrido a un método empírico, mediante encuestas y trabajos de campo realizados en empresas de agua potable de los principales destinos turísticos de la Comunidad Valenciana. Con la colaboración de estas empresas, se han analizado los principales sistemas de abastecimiento para valorar las tendencias de consumo, la estacionalidad, el rendimiento técnico de las redes y el ciclo integral del agua. Asimismo, se incluyen resultados sobre el consumo de agua realizado en hoteles, en sus diferentes categorías. También en las distintas categorías de viviendas ocupadas por turistas y residentes en periodos de vacaciones, y en otros establecimientos vinculados a las actividades turísticas (restaurantes, camping, etc).

Palabras clave: actividad turística, modelos urbanos de baja densidad, consumo de agua, abastecimientos urbanos, trasvases, desalación,

\section{ABSTRACT}

The analysis of water consumption units associated with tourist activities turns out to be indispensable to value environmental and socioeconomic efficiency of valencian

\footnotetext{
1 Algunas de las informaciones recogidas en este trabajo fueron elaboradas por el autor para la realización del proyecto de investigación sobre «Estudio piloto de análisis económico del uso del agua en la industria, usos recreativos y otros usos», desarrollado por el Instituto Universitario de Geografía de la Universidad de Alicante para el Ministerio de Medio Ambiente en 2004.
} 
model of territorial, urban and tourist development.This research analyzes urban and tourist water consumption on different forms of these activities territorial implantation, specially on hotel and residential housing modalidades, comparing efficiency of drinkable water in low density and high density urban models. To achieve the mentioned purpose, it has been resorted to an empirical method, by means of surveys and fieldworks realized to drinkable water companies on principal tourist destinations of Valencian Region. With these companies collaboration, it has been analyzed principal systems of supply in order to value consumption trends, seasonal variation, nets technical performance and wate integral cycle.Likewise, this research has offered new results on water consumption realized by hotels and on its different categories. Also by housings different categories occupied by tourists and residents on holidays periods and by other establishments linked to the tourist activities (restaurants, camping, etc.).

Key words: tourism activity, low-density urbanisation model, water consumption, urban water supplies, transfers, desalination,

\section{Introducción: la caracterización de las demandas de agua urbano-turísticas}

Las actividades de ocio, turismo y de segundas residencias han adquirido una importancia de primer orden en la evolución de las demandas de agua de muchas regiones españolas, entre las cuales se encuentra la Comunidad Valenciana, que se ha convertido en uno de los principales destinos turísticos del Mediterráneo occidental. La fuerte expansión de estas funciones económicas en municipios costeros ha propiciado la configuración de una dorsal de poblamiento urbano-turística que se prolonga con bastante continuidad desde las planas de Vinaroz y Benicarló, en Castellón, hasta la franja litoral de Torrevieja, Orihuela y Pilar de la Horadada, en la comarca alicantina del Bajo Segura. Esta dorsal, que constituye el principal eje de desarrollo territorial de la región valenciana, acoge diferentes tipologías de alojamiento, equipamientos y servicios que han multiplicado los consumos de agua potable durante las últimas décadas. La caracterización de este tipo de demandas resulta fundamental para plantear estrategias integradas de gestión de los recursos hídricos y de ordenación del territorio en zonas con fuerte implantación de actividades turísticas, de ocio y residenciales, más aún cuando se dan cita problemas de escasez, contaminación y de competencia con otros usos del agua como los agrícolas. De entrada, existe una limitación de orden estadístico e incluso conceptual a la hora de diferenciar el gasto de agua que efectúan los usos turísticos en espacios costeros, ya que los sistemas de abastecimiento pueden satisfacer otras demandas urbanas que no responden exclusivamente a este tipo de actividad. La propia definición que maneja la Organización Mundial de Turismo (OMT) sobre el significado de «turismo» asume de forma implícita esta dificultad ya que éste comprende «las actividades que realizan las personas durante sus viajes y estancias en lugares distintos al de su entorno habitual, por un período de tiempo consecutivo inferior a un año, con fines de ocio, por negocios y otros motivos». Así, no sólo se consideran las actividades que realizan los desplazados con fines de ocio, sino también las que se realizan por negocios y por otros motivos. La dificultad es todavía mayor cuando se pretende cuantificar las implicaciones socioeconómicas y territoriales de las actividades turísticas en los diversos ámbitos en los que se implanta, especialmente cuando se pretende manejar escalas de análisis comarcal y local.

En el apartado de patrones de consumo, resulta indispensable conocer y diferenciar el uso del agua que realizan los turistas, residentes o veraneantes del que efectúan los 
residentes habituales. Además, en la Comunidad Valenciana y en otras regiones españolas debe añadirse que gran parte de los turistas que llegan a los principales destinos se aloja en viviendas no regladas a los efectos administrativos o fiscales. Tampoco se dispone de un censo de viviendas de uso turístico, ni de información sobre días de ocupación, número de personas alojadas, etc.

El agua es un recurso natural que reviste carácter estratégico para las actividades turísticas, más aún cuando su disponibilidad no se encuentra garantizada. Es fundamental para los abastecimientos de agua potable, para algunas instalaciones recreativas y de ocio, y como factor definitorio del paisaje dominante en determinados espacios naturales. Los recursos de agua pueden influir en la elección de los destinos turísticos, más aún cuando se dan cita problemas de escasez o mala calidad del agua. Uno de los principales «turoperadores» de Europa, el grupo TUI, a través de su División de Medio Ambiente, ha establecido una serie de criterios ambientales para la selección de destinos vacacionales, entre los cuales se encuentra el abastecimiento de agua potable, el tratamiento de aguas residuales o la calidad de las playas y del agua en los lugares de baño. Este hecho obliga a adoptar nuevos criterios que permitan optimizar la gestión de los recursos de agua en los distintos modelos de implantación territorial del turismo, para satisfacer las exigencias de cualificación y sostenibilidad del sector (Vera Rebollo, J.F. 2006).

La disponibilidad de agua también puede condicionar la propia oferta de servicios y productos turísticos, como podría ser campos de golf, piscinas, complejos acuáticos de ocio, jardines, etc. Por su parte, la relación entre la actividad turística y el agua adquiere particular complejidad en la Comunidad Valenciana por la difusión del modelo turístico de «sol y playa». En este caso, al creciente volumen de viajeros turísticos que demandan oferta de alojamiento hotelera y extrahotelera se suma las presión demográfica derivada del crecimiento de la población permanente que reside en la zona. En este sentido, el Libro Blanco del Agua en España señalaba (2000) que, aunque es previsible un estancamiento de la población española en el corto y medio plazo que hace que no sean probables los incrementos globales significativos en las necesidades hídricas del abastecimiento a poblaciones en España, éstos sí podrían ser relevantes en algunas regiones costeras como la Comunidad Valenciana. Esta tendencia se ha evidenciado durante la última década en los principales destinos turísticos costeros del litoral mediterráneo español, con fuerte crecimiento de la vertiente residencial asociada a espacios vacacionales. La actividad inmobiliaria se ha intensificado durante la última década en todas las provincias mediterráneas, desde Girona a Málaga, incluyendo Baleares, si bien, a partir de 2007 se ha acusado una notoria desaceleración de la construcción, sobre todo de segundas residencias en espacios vacacionales. Esta inflexión ha puesto fin a una etapa de fuerte dinamismo en la construcción en toda la fachada mediterránea española, como evidencian los datos de certificación de fin de obra de vivienda nueva, con más de 2 millones de unidades construidas durante el periodo 2000-2006. En provincias como Girona, Castellón, Almería, Granada o Murcia se han triplicado las viviendas construidas en 2006 en comparación con las edificadas en el año 2000, mientras que en otras como Alicante, Baleares o Málaga se han mantenido los niveles de construcción.

La repercusión de la actividad inmobiliaria sobre el consumo de agua potable ofrece una gran diversidad de situaciones, si bien todas ellas ofrecen el denominador común de intensificar la presión sobre los recursos hídricos y sobre los sistemas de distribución, tanto en alta como en baja. En los principales destinos turísticos vacacionales, los abastecimientos de agua potable se han resuelto mediante la configuración de complejos sistemas de captación y distribución en alta, gestionados por mancomunidades (Canales del Taibilla), consorcios (Ter-Llobregat, Campo de Tarragona, Marina Baja) y entidades privadas o mixtas 
Cuadro $\mathrm{n}^{\circ} 1$

LA CONSTRUCCIÓN DE VIVIENDAS EN PROVINCIAS DE LA FACHADA

MEDITERRÁNEA ESPAÑOLA.

COMPARACIÓN DE LOS AÑOS 2000 Y 2006

\begin{tabular}{|l|r|r|r|r|r|r|}
\hline & \multicolumn{3}{|c|}{ AÑO 2000 } & \multicolumn{3}{c|}{ AÑO 2006 } \\
\hline Provincias & \multicolumn{1}{|c|}{ Unifamiliar } & \multicolumn{1}{|c|}{ En bloque } & \multicolumn{1}{c|}{ Total } & \multicolumn{1}{c|}{ Unifamiliar } & \multicolumn{1}{c|}{ En bloque } & \multicolumn{1}{c|}{ Total } \\
\hline Alicante & 18.215 & 24.021 & 42.236 & 6.657 & 34.939 & 41.596 \\
\hline Almería & 3.593 & 6.801 & 10.394 & 4.029 & 20.105 & 24.134 \\
\hline Baleares & 4.522 & 10.617 & 15.139 & 2.657 & 13.195 & 15.852 \\
\hline Barcelona & 10.115 & 31.712 & 41.827 & 8.641 & 56.514 & 65.155 \\
\hline Castellón & 2.305 & 9.267 & 11.572 & 2.911 & 29.774 & 32.685 \\
\hline Girona & 4.845 & 6.648 & 11.493 & 5.840 & 16.431 & 22.271 \\
\hline Granada & 5.894 & 5.730 & 11.624 & 6.146 & 18.013 & 24.159 \\
\hline Málaga & 7.328 & 27.985 & 35.313 & 8.185 & 30.014 & 38.199 \\
\hline Murcia & 6.360 & 11.987 & 18.347 & 5.201 & 46.135 & 51.336 \\
\hline Tarragona & 1.948 & 13.568 & 15.516 & 5.421 & 19.285 & 24.706 \\
\hline Valencia & 6.897 & 21.249 & 28.146 & 7.574 & 38.786 & 46.360 \\
\hline & 72.022 & 169.585 & 241.607 & 63.262 & 323.191 & 386.453 \\
\hline
\end{tabular}

Fuente: Ministerio de Fomento, 2007.

(Aguas de Barcelona, Aguas de Valencia o Aguas de Alicante), que distribuyen recursos alóctonos superficiales e hipogeos trasvasados desde otras cuencas (Ter-Llobregat, EbroCampo de Tarragona, Júcar-Turia, Tajo-Segura, Alto Vinalopó-Campo de Alicante). La mayoría de estos sistemas han alcanzado límites críticos en la garantía de los suministros actuales, más aún durante situaciones de sequía, lo que ha propiciado la construcción de un gran número de desaladoras en todo el litoral mediterráneo, desde Barcelona a Málaga, con iniciativas impulsadas por el Ministerio de Medio Ambiente (Programa A.G.U.A.) y por los propios promotores inmobiliarios, que servirían también para atender nuevas demandas urbano-turísticas.

Aunque las fuentes no convencionales (desalación y reutilización de residuales) podrían proporcionar los recursos de agua necesarios para continuar con la expansión del alojamiento hotelero y extrahotelero, debe hacerse notar que durante los últimos años se ha abierto un intenso debate sobre la necesidad de limitar las demandas urbano-turísticas mediante políticas de Ordenación del Territorio. De hecho, a escala autonómica y nacional, se han promulgado diferentes normas que condicionan la expansión de nuevas áreas urbanas a que se garantice la disponibilidad de agua suficiente. Así ocurre con la Ley 4/2004, de 30 de junio, de Ordenación del Territorio y Protección del Paisaje de la Comunidad Valenciana (LOTPP), con la Ley 11/2005, de 22 de junio, de modificación del Plan Hidrológico Nacional o con la propia Ley 8/2007, de 28 de mayo, de suelo, que exige el preceptivo informe de la Administración Hidrológica sobre la existencia de recursos hídricos suficientes para satisfacer las nuevas demandas (Art. 15). En íntima relación con la orientación de estas leyes, durante los próximos años cabría avanzar en la definición de modelos territoriales asociados al alojamiento hotelero y extrahotelero atendiendo a la eficiencia en el consumo 
de agua. Por ejemplo, en los modelos de urbanización difusa con predominio de viviendas unifamiliares con jardín y piscinas de uso estacional, se elevan los consumos y se reduce el rendimiento técnico en comparación con los continuos urbanos de alta densidad con viviendas construidas en bloque. Este hecho merece una especial atención ya que una parte significativa de las viviendas construidas en las provincias del litoral mediterráneo español durante la última década se ha dedicado a residencias unifamiliares, muchas de ellas de uso estacional, si bien, con una tendencia decreciente motivada por el fuerte incremento del precio del suelo. Así, si en el año 2000 se edificaron 72.022 viviendas unifamiliares, que suponían el $29,8 \%$ del total construido en estas provincias, en 2006 se redujeron a 63.262 unidades que representaban el $16 \%$ del total.

La definición de los modelos urbanización e implantación de las actividades turísticas más eficientes en términos de gasto de agua, requiere un conocimiento empírico de las tipologías de consumo, tanto en la oferta de alojamiento hotelera como extrahotelera. Este objetivo está también respaldado por la propia Directiva Marco del Agua 2000/60/CE, cuya transposición al ordenamiento jurídico español en 2003 ha obligado durante los últimos años a realizar nuevos estudios de las diferentes demarcaciones hidrográficas, para valorar el impacto de las actividades humanas en las masas de agua junto con un análisis económico de los usos (Art. 5). Son varios los fines de estos trabajos, aunque destaca la elaboración y aprobación de los nuevos Planes Hidrológicos de cuenca por demarcaciones hidrográficas (Art. 13) antes de diciembre de 2009, y el establecimiento de una política de precios que incentive un uso adecuado del agua para cumplir con los objetivos ambientales de la Directiva antes de diciembre de 2010 (Art. 9).

\section{Propuestas metodológicas para la caracterización de las demandas de agua urba- no-turísticas}

En España, no existen datos estadísticos que abarquen la totalidad de los suministros urbanos en la escala local ni tampoco datos diferenciados de consumo por tipologías de vivienda o de establecimientos vinculados con las actividades turísticas y de ocio. Por ejemplo, la Encuesta Nacional de la Asociación Española de Abastecimientos y Saneamiento (AEAS), que es el conjunto de datos de mayor alcance dentro del territorio nacional, no cubre a toda la población abastecida. Si la encuesta de 2002 fue contestada por 759 municipios que suponían el $67 \%$ de la población nacional, en la de 2004 sólo se recibieron 629 cuestionarios que cubrían el $59 \%$ de la población. El grado de cobertura en las principales regiones turísticas fue del $68 \%$ en la Comunidad Valenciana, $66 \%$ en Cataluña, $64 \%$ en Baleares, $54 \%$ en Murcia y $44 \%$ en Andalucía (AEAS, 2004). Por otro lado, al igual que ocurre con las informaciones que maneja el Instituto Nacional de Estadística, los datos e informaciones que aportan estas fuentes están agregados a escala nacional, regional o provincial. De ahí, que en la escala local no se disponga de información detallada sobre los consumos reales de agua potable. Esta limitación estadística impide conocer el origen del recurso utilizado, la estructura de la demanda, el área atendida, los abonados o las viviendas conectados a la red, las tendencias de consumo, la estacionalidad, la situación del saneamiento, la depuración o la reutilización de residuales.

Para suplir las limitaciones que ofrecen las fuentes estadísticas puede recurrirse a diversos métodos. En primer lugar, la realización de encuestas en las entidades encargadas del abastecimiento con la finalidad de integrar toda la información territorial (población, viviendas, actividad turística) con la existente sobre gestión y consumo de agua. En la distribución en alta, desde las fuentes de captación a los depósitos municipales, resulta fundamental explicar el origen del recurso, sus condiciones de calidad y cantidad, precios 
en origen, infraestructura de distribución (conducciones, depósitos reguladores, pozos, etc), características y régimen de explotación por parte de las empresas suministradoras. Es también esencial acceder a series históricas de consumo en alta y en baja para valorar cómo ha evolucionado la eficiencia en la gestión por parte de las empresas. En el apartado de la distribución en baja, es decir, desde los depósitos municipales a las viviendas, es importante conocer el régimen de explotación, series históricas de gasto anuales y mensuales para evaluar la estacionalidad, volúmenes de agua registrados y facturados, usuarios conectados, tarifas de venta, red de saneamiento, depuración de aguas residuales y destino de las mismas.

Por otro lado, hay dificultades añadidas que surgen a la hora de diferenciar las demandas urbanas generadas por la población permanente, de las industriales o las propiamente turísticas. En efecto, no es frecuente que las empresas distingan con tanta precisión el destino final del caudal suministrado en baja. A veces, esos datos obedecen más a estimaciones que a cómputos exactos de consumo. Diferenciar qué parte corresponde a cada tipo de consumo no es tarea fácil, ya que ello obligaría a disponer de datos pormenorizados por unidades de consumo y por sectores urbanos atendidos. En el caso concreto los usos turísticos del agua las informaciones de consumo de agua potable deben correlacionarse con datos de ocupación real de la oferta de alojamiento hotelera y extrahotelera. En el caso de la oferta de alojamiento hotelera es posible acceder a datos reales de ocupación. La dificultad es todavía mayor para acceder a estimaciones sobre la ocupación de la oferta extrahotelera. Se dispone de censos (INE) sobre las viviendas secundarias y sobre vacías, pero en este último caso también abundan las residencias que se ocupan durante periodos vacacionales. Dada la complejidad existente para conocer el alcance real de la ocupación turística en la oferta de alojamiento extrahotelera - apartamentos, viviendas unifamiliares, etc. - , existe una alternativa para la determinación de la demanda urbana en municipios turísticos, con carácter prospectivo. Si se dispone de información relativa a consumos por municipios y usuarios, se puede establecer una dotación media por vivienda o por abonado. Debe advertirse que esa dotación media también entraña dificultades por la existencia de distintos tipos de abonados (residenciales, industriales, colectivos, municipales) que inciden en el valor de consumo promediado, aunque en municipios de clara vocación turística y residencial se suelen alcanzar resultados diferentes a los obtenidos en zonas con otras actividades productivas, sobre todo en el apartado de estacionalidad.

Asimismo, las dotaciones medias por viviendas censadas obtenidas a partir de consumos reales, refleja la situación actual del municipio analizado, y puede ayudar a establecer tendencias de futuro a partir de variables como las certificaciones de fin de obra de viviendas. Aún así, no deja de ser una estimación estadística basada en la extrapolación de población o de viviendas construidas, que lleva aparejadas ciertas imprecisiones ya que los métodos estadísticos no pueden recoger todos los factores de demanda incidentes en el consumo de agua, particularmente los relativos a modelos económicos y territoriales. Para conocer las dotaciones actuales y futuras para cada una de las poblaciones representativas se parte de los siguientes datos, siempre que se disponga de ellos:

- Suministro anual y su distribución mensual en $\mathrm{m}^{3}$.

- Población permanente y estacional, vinculada a viviendas censadas.

- Datos de certificaciones fin de obra de vivienda construida.

- Tendencias de evolución de viviendas censadas y de viviendas construidas, para valorar posibles escenarios de futuro en las demandas urbanas. 
La calidad y fiabilidad de los datos de consumo ha mejorado notablemente durante la última década, debido a los esfuerzos realizados por las empresas de agua potable en la tecnificación de los sistemas de distribución y de gestión. En muchos municipios turísticos se ha mejorado el rendimiento hidráulico de las redes, a partir de un mayor control del agua registrada a los usuarios y del agua no registrada. Dicho rendimiento hidráulico se mide como un cociente entre $\mathrm{R}$ (Agua registrada a los usuarios) y $\mathrm{S}$ (Agua entregada o suministrada a la red) y en porcentaje, es decir R / S * 100 (Vid. cuadro $n^{\circ} 2$ ). Para estimar el rendimiento de las redes de distribución se deben ponderar otras variables que pueden condicionar una mayor menor eficiencia técnica, como es la longitud de la red de distribución, su antigüedad y el estado de conservación y el número de acometidas que tiene la misma. Las empresas concesionarias del servicio de agua potable han desarrollado planes de actuación para aumentar el volumen de agua registrada y reducir el de agua suministrada o inyectada a la red. En la mayoría de las ciudades con más de 10.000 habitantes se han modernizado y tecnificado los sistemas de control de la red, recurriendo para ello a los Sistemas de Información Geográfica y de Telecontrol, para establecer una zonificación de la red y de las áreas de uso atendidas, asignando a cada usuario a una de estas áreas.

La zonificación de la red se acompaña de la implantación de caudalímetros y controladores de presión para la detección y localización de fugas, que también puede realizarse mediante dispositivos de escucha nocturna para su reparación. Otra medida que propicia el ahorro de agua es la revisión periódica de los contadores, ya que el exceso de cal puede perjudicar la medición del consumo real, provocando el llamado «subcontaje». Según han confirmado las encuestas realizadas, la mayoría de las pérdidas que se produce en la entrega a viviendas y otros consumidores urbanos se produce en los collarines de toma, en parte debido a su antigüedad, y también por el empleo de materiales como plomo o fibrocemento que sufren un fuerte deterioro y arrojan grandes fugas.

\section{Cuadro $\mathrm{n}^{\circ} 2$}

ESTRUCTURA DEL CONSUMO Y VALORACIÓN DEL RENDIMIENTO TÉCNICO DE LOS SISTEMAS DE ABASTECIMIENTO DE AGUA POTABLE

\begin{tabular}{|c|c|}
\hline AGUA REGISTRADA A LOS USUARIOS & $\begin{array}{l}\text { AGUA NO REGISTRADA A LOS } \\
\text { USUARIOS }\end{array}$ \\
\hline $\begin{array}{l}\text { - Consumos domésticos } \\
\text { - Consumos industriales } \\
\text { - Consumos comerciales } \\
\text { - Consumos de instituciones oficiales } \\
\text { - Consumos públicos: } \\
\text { - Parques de bomberos } \\
\text { - Suministros a parques y jardines } \\
\text { - Fuentes y pilares }\end{array}$ & $\begin{array}{l}\text { Consumos públicos: } \\
\text { - Limpieza y baldeo de calles. } \\
\text { - Riego de jardines. } \\
\text { - Fuentes públicas. } \\
\text { - Consumos propios de la red: } \\
\text { - Limpieza de la red de saneamiento. } \\
\text { - Subcontaje de contadores. } \\
\text { - Fugas en conducciones. } \\
\text { - Consumos de particulares } \\
\text { - Fraudes } \\
\text { - Riego de jardines privados. } \\
\text { - Sistemas contra incendios. }\end{array}$ \\
\hline
\end{tabular}

ANR $($ Agua No Registrada $)=\mathrm{S}($ Agua suministrada a la red $)-\mathrm{R}($ Agua registrada a los usuarios)

Fuente: Alonso, JJ. 2006 (Aquagest). 
Una de los principales rasgos distintivos del consumo turístico de agua en el alojamiento extrahotelero es la estacionalidad, que se debe a un tipo de poblamiento vacacional que suele practicarse en apartamentos y, sobre todo, en viviendas no principales en propiedad o alquiladas que no son consideradas en las estadísticas oficiales. Para distinguir consumos según tipos de vivienda se han manejado datos de facturación de los principales destinos turísticos valencianos, entre los cuales conviene destacar el municipio de Benidorm. Se han obtenido datos de facturación atendiendo a tipos de vivienda (unifamiliar y en bloque) y al carácter del poblamiento (permanente y estacional). Según estas informaciones, el gasto de agua potable facturado por unidades de consumo sería el siguiente:

- Viviendas principales: 663 litros/vivienda/día.

- Viviendas secundarias: 536 litros/vivienda/día.

Debe hacerse notar que en el poblamiento estacional, existe una gran diferencia entre las viviendas unifamiliares y las construidas en bloque. Así, las unifamiliares con poblamiento estacional pueden alcanzar una facturación de 865 litros/vivienda/día, mientras que en las construidas en bloque ese consumo medio anual desciende a 208 litros/vivienda/día. Semejantes diferencias se hacen también patentes en el poblamiento permanente, donde las viviendas unifamiliares arrojan un consumo medio en facturación de 891 litros/vivienda/día, frente a los 436 litros/vivienda/día cuando se trata de viviendas en bloque. A medio plazo, otra de las fórmulas que podría seguirse para concretar más si cabe el consumo urbanoturístico de agua sería conocer con detalle y a escala municipal la distribución de viviendas por tipología y por forma de poblamiento. A partir de estos datos, se puede estimar el gasto de agua (litros/vivienda/día) con los volúmenes facturados en las distintas categorías. Estos módulos de consumo por vivienda también pueden ser traducidos a gasto por persona y día. Los resultados obtenidos por facturación, indican que en unidades familiares compuestas por 3 o por 4 miembros en poblamiento permanente, se alcanzan módulos que oscilan de 140 a 180 1/hab/día si la vivienda esta en bloque, y puede acercarse a 300 1/hab/día en unifamiliar. En poblamiento estacional se dan mayores diferencias, ya que el consumo sólo se activa durante unos meses, y se pueden encontrar módulos personales de unos 175 1/hab/día en viviendas en bloque, que pueden crecer a 600 1/hab/día en residencias unifamiliares con jardín y piscina.

Cuando no se dispone de datos de facturación pormenorizados por usos ni por tipologías de residencia, se puede realizar otra estimación del gasto de agua a partir de los volúmenes suministrados a la red en alta y los registrados en baja, con módulos de consumo por vivienda (Fernández-Montes, C. y otros, 2003). Debe advertirse que en este caso esos módulos (litros/vivienda/día) expresarán el consumo de agua potable suministrado y registrado del municipio incluyendo todos los usos, desde los propiamente domésticos a los industriales o los municipales. Con datos de suministro y de registro en baja de los años 2000 a 2002 de diversos municipios costeros de la Comunidad Valenciana, que incluyen destinos turísticos, vacacionales, mixtos y otros municipios con funciones económicas y de servicios ajenas a las actividades del ocio y turismo, se han obtenido módulos de 542 y 375 litros/vivienda/día para el consumo en alta y en baja, respectivamente. Obviamente, además de que son valores medios, la diferencia entre uno y otro módulo se debe a que el volumen registrado en baja siempre es inferior al volumen suministrado a la red. Así, el rendimiento técnico de estos sistemas se situaba en el $72 \%$ del volumen suministrado a la red, si bien, en municipios con abundante oferta de alojamiento hotelera como Benidorm (91 $\%)$ o extrahotelera como Alfaz del Pí (80 \%) y Alboraia+Port Saplaya (78 \%) el volumen registrado y facturado es muy superior. 


$$
\text { Cuadro }{ }^{\circ} 3
$$

CONSUMOS DE AGUA POTABLE EN MUNICIPIOS COSTEROS Y DE SEGUNDA LÍNEA DE LA COMUNIDAD VALENCIANA (2000-2002)

\begin{tabular}{|c|c|c|c|c|c|}
\hline & \multicolumn{2}{|c|}{ CONSUMO ALTA } & \multicolumn{2}{|c|}{ CONSUMO BAJA } & \multirow{2}{*}{$\begin{array}{c}\text { RENDI- } \\
\text { MIENTO } \\
\%\end{array}$} \\
\hline MUNICIPIO & $\begin{array}{l}\text { VOLUMEN M } \\
\text { SUMINISTRADO }\end{array}$ & $\begin{array}{l}\text { L/VIV/ } \\
\text { DÍA }\end{array}$ & $\begin{array}{l}\text { VOLUMEN M } \\
\text { REGISTRADO }\end{array}$ & $\begin{array}{l}\text { L/VIV/ } \\
\text { DÍA }\end{array}$ & \\
\hline ALFAZ DEL PI & 2.206 .322 & 594 & 1.774 .464 & 478 & 80 \\
\hline ALTEA & 2.449 .932 & 551 & 1.978 .107 & 445 & 80 \\
\hline BENIDORM & 12.348 .727 & 657 & 11.212 .510 & 597 & 91 \\
\hline BENISA & 1.563 .372 & 501 & 1.114 .255 & 357 & 71 \\
\hline ELCHE & 16.877 .996 & 512 & 12.996 .057 & 394 & 77 \\
\hline FINESTRAT & 593.876 & 495 & 569.088 & 473 & 96 \\
\hline POLOP & 397.067 & 660 & 270.843 & 450 & 68 \\
\hline MUTXAMEL & 1.489 .725 & 574 & 1.087 .500 & 419 & 73 \\
\hline VILLAJOYOSA & 2.516 .086 & 491 & 1.776 .475 & 347 & 70 \\
\hline ALMAZORA & 1.880 .000 & 553 & 1.460 .000 & 430 & 77 \\
\hline CASTELLÓN & 20.525 .129 & 770 & 15.642 .201 & 587 & 76 \\
\hline MONCÓFAR & 728.360 & 481 & 492.713 & 325 & 68 \\
\hline OROPESA & 1.643 .816 & 336 & 953.555 & 195 & 58 \\
\hline PEÑISCOLA & 2.259 .000 & 462 & 1.719 .827 & 352 & 76 \\
\hline TORREBLANCA & 650.000 & 460 & 455.000 & 322 & 70 \\
\hline $\begin{array}{l}\text { ALBORAYA+PORT } \\
\text { SAPLAYA }\end{array}$ & 1.469 .410 & 422 & 1.087 .971 & 312 & 78 \\
\hline ALBUIXEC & 238.048 & 426 & 124.194 & 222 & 89 \\
\hline CULLERA & 3.950 .886 & 419 & 2.607 .585 & 277 & 66 \\
\hline GANDÍA & 9.540 .000 & 528 & 6.397 .322 & 354 & 68 \\
\hline SAGUNTO & 6.628 .660 & 560 & 4.215 .323 & 356 & 64 \\
\hline SUECA & 8.134 .335 & 993 & 2.440 .301 & 298 & 30 \\
\hline VALENCIA & 68.800 .196 & 499 & 46.197.241 & 335 & 68 \\
\hline XERACO & 1.079 .276 & 514 & 647.566 & 308 & 60 \\
\hline COM.VALENCIANA & & 542 & & 375 & 72 \\
\hline
\end{tabular}

Fuente: Instituto Universitario de Geografía (2004): «Estudio piloto de análisis económico del uso del agua en la industria, usos recreativos y otros usos». Ministerio de Medio Ambiente. 
En estos casos, los módulos en baja se aproximan a los obtenidos en alta, con valor máximo en Benidorm, con 597 litros/vivienda/día, y mínimo en Oropesa, con 195 litros/ vivienda/día (Vid. cuadro $\mathrm{n}^{\circ} 3$ ). También se ha difundido la imagen estereotipada de que los municipios turísticos gestionan peor y consumen más agua que los del interior, y esto no ocurre así en modo alguno. De hecho, con series de suministro y facturación de 25 municipios del interior valenciano, se han obtenido módulos de 571 y 390 litros/vivienda/día en el gasto de agua en alta y en baja, respectivamente. Por otro lado el rendimiento medio desciende al $70 \%$, y tan sólo dos de los municipios analizados, en este caso Alcasser y Catarroja, superaban el $80 \%$ de rendimiento.

Con los diferentes datos de consumo que se pueden obtener, tanto en $\mathrm{m}^{3} /$ vivienda/día como en 1/habitante/día, se pueden establecer tendencias de futuro en las demandas multiplicando las dotaciones por vivienda y por habitante previstos en las figuras de planeamiento para cada municipio en los distintos horizontes temporales. Por ejemplo, en las proyecciones de demanda para los usos urbano-turísticos realizadas en 2004 por el Instituto Universitario de Geografía de la Universidad de Alicante y el Ministerio de Medio Ambiente para la cuenca piloto del Júcar (Art. 5) se manejó el horizonte del año 2015, ya que en esta fecha deberían alcanzarse los objetivos ambientales previstos en la Directiva Marco del Agua 2000/60/CE (Art. 4). Es de notar que esta proyección estadística requiere como hipótesis de partida que se mantengan las tendencias de los censos de población y vivienda. En el caso valenciano otras variables a considerar serían la evolución del mercado de la vivienda, condicionado en gran medida por la demanda de segundas residencias, y por las estrategias de los municipios a partir del planeamiento, para restringir o permitir el desarrollo de más suelo para urbanizar. A partir de los consumos de agua por vivienda, se puede estimar que en 2001 la Comunidad Valenciana precisaría un volumen de agua de $566 \mathrm{hm}^{3}$ para atender todas las demandas urbanas y turísticas. Asimismo, si se mantuviese la misma tendencia registrada en los últimos censos de vivienda, el consumo de agua potable crecería de 566 a $685 \mathrm{hm}^{3}$ para 2015, en todo el territorio valenciano. Estas expectativas de crecimiento del consumo de agua potable son mucho mayores si se considera la evolución de las certificaciones fin de obra de viviendas construidas en el periodo 1992-2002. Mediante esta variable, si se proyectan las tendencias de incremento de agua potable para el horizonte del año 2015, el volumen adicional requerido superaría los 200 hm³/año en comparación con el consumo de 2001 (Gil Olcina, A. y Rico Amorós, A.M. 2007).

\section{Los usos urbano-turísticos del agua y la necesidad de considerar modelos locales para caracterizar los sistemas de abastecimientos en municipios turísticos.}

Durante la segunda mitad del pasado siglo y primeros años del presente, la Comunidad Valenciana ha experimentado un fuerte desarrollo socioeconómico y, junto a ello, una intensificación de todas las demandas de agua, particularmente de las urbano-turísticas. Este desarrollo territorial ha determinado que el $77 \%$ de la población valenciana se concentre en una dorsal de poblamiento que se prolonga desde la plana costera de Vinaroz-Benicarló, al norte de Castellón, hasta el Pilar de La Horadada, en el litoral sur alicantino. Para atender la creciente demanda de agua potable se han configurado complejos sistemas de distribución en alta, que captan y transportan a veces a gran distancia aguas superficiales, subterráneas y residuales depuradas. Debe hacerse notar que sobre las demandas turísticas se tiene una imagen estereotipada, que se vincula a consumos excesivos. A ello se une que el turismo se ha convertido en una de las principales actividades económicas de la Comunidad Valenciana, en un eje de poblamiento que se extiende desde Benicarló a Pilar de la Horadada, e incluye también municipios de segunda línea. En esta dorsal se ha producido un fuerte 
desarrollo de alojamiento hotelero, apartamentos, campings y segundas residencias para veraneo y residentes extranjeros, que sitúa a la Comunidad Valenciana entre las regiones de mayor proyección turística de España. Se ha estimado que en su territorio existen más de 2 millones de plazas en viviendas, apartamentos turísticos y de segunda residencia, mientras que la oferta de alojamiento hotelera se acercaba a las 120.000 plazas, distribuidas en unos 860 establecimientos, que recibieron alrededor de 7,6 millones de viajeros y generaron 24,8 millones de pernoctaciones en 2006. Así, la prestación de servicios turísticos y de ocio se ha convertido en uno de los principales motores de la economía valenciana, de manera que, en 2005, generaba el 13,8 \% del PIB, con más de 12.000 millones de euros de ingresos y 290.000 empleos directos e indirectos (CT, 2006).

El territorio valenciano es pionero en España en la configuración de grandes sistemas de distribución de agua potable en alta, como ocurre con las empresas Aguas de Valencia (1890), Aguas Municipalizadas de Alicante (1898) y Fomento Agrícola Castellonense (1872) cuya creación data de finales del siglo XIX, a las que se unieron otras entidades como la Mancomunidad de los Canales del Taibilla (1927) y el Consorcio de Aguas de la Marina Baja (1977). En la actualidad, son muy pocas las ciudades valencianas que distribuyen a sus habitantes aguas potables captadas en sus propios términos municipales. La mayoría de ellas dependen de recursos hídricos procedentes de ríos o acuíferos localizados en comarcas o regiones distantes a veces cientos de kilómetros. Sucede así con los recursos procedentes del Alto Tajo que distribuye la Mancomunidad de los Canales del Taibilla, a partir del trasvase Tajo-Segura, con los aportados por el trasvase Júcar-Turia para el abastecimiento del área metropolitana de Valencia y con los viajes de agua practicados desde finales del XIX desde los acuíferos del Alto Vinalopó a Alicante y Elche. Las últimas décadas del siglo XX han conocido un intenso proceso de concentración empresarial de la gestión del agua potable, tanto en los suministros en baja como en alta. En este proceso se ha afianzado la posición estratégica de diferentes grupos empresariales, en algún caso con presencia de multinacionales francesas pero también de constructoras y entidades bancarias españolas, que permite explicar el mapa institucional de la gestión del agua potable en alta y en baja en los principales destinos turísticos valencianos. Por ejemplo, en territorio de Castellón, las principales áreas de uso urbano-turístico se hallan en la Plana Baja, Plana Alta y Bajo Maestrazgo, y la empresa privada más destacada se denomina FACSA (Fomento Agrícola Castellonense S.A.), que distribuye aguas hipogeas a 37 municipios y más de medio millón de habitantes, entre los cuales se encuentran municipios costeros con creciente presencia de poblamiento residencial y turístico como Peñíscola, Oropesa del Mar, Cabanes, Torreblanca, Moncófar Alcalá de Xivert, Benicarló, Benicasim y Castellón de la Plana.

La gestión de agua potable en la provincia de Valencia, corresponde, en gran medida, al grupo Aguas de Valencia, si bien, durante la última década AGBAR (Aguas de Barcelona) y Aqualia (FCC) también han emprendido una fuerte expansión en este territorio. La distribución en alta de Valencia y su área metropolitana es realizada fundamentalmente por Aguas de Valencia, que cuenta para ello con las aguas del trasvase Júcar-Turia, las que puede derivar del Turia en la Presa, más las aportadas por media docena de pozos, alguno de ellos con problema de nitratos que impide su utilización. Durante los últimos años, el promedio de agua distribuida en alta por Aguas de Valencia a los 43 municipios del área metropolitana asciende a $110 \mathrm{hm}^{3}$. Este sistema metropolitano de distribución ha venido a corregir los graves problemas de suministro que padecían hace algunos años núcleos como el Puig, en 1’Horta Nord, que en 1989 dependía de 11 captaciones, de las cuales el ayuntamiento gestionaba dos. Las restantes pertenecían a urbanizaciones como Medicalia, Puigval, Playpuig, Mar Plata, etc, que se abastecían de pozos de su propiedad, con aguas de calidad deficiente por su elevada salinidad y contenido en nitratos. Y sucedía igual en 
la Pobla de Farnals, donde su núcleo urbano principal consumía en 1989 un volumen de $410.625 \mathrm{~m}^{3}$ procedentes de una captación del ayuntamiento, mientras que las urbanizaciones de la playa se suministraban de pozos propios (Rico Amorós, A. M. 1998).

En la provincia de Alicante, la insuficiencia de agua que padece gran parte de su territorio, unida al incremento del consumo para atender usos urbano-turísticos de gran repercusión social y económica, han determinado que las ciudades más importantes distribuyan a sus habitantes aguas captadas a veces a cientos de kilómetros. El ejemplo más destacado es la Mancomunidad de los Canales del Taibilla, que distribuye las aguas del trasvase Tajo-Segura y constituye uno de los mayores complejos hidráulicos de España para el abastecimiento a poblaciones. Fue creada por el R.D. Ley de 4 de octubre de 1927, con el Conde de Guadalhorce en Fomento. El proyecto de obras, relativo a la conducción de agua potable, preveía contar con 2’ $5 \mathrm{~m}^{3} / \mathrm{s}$ de caudal derivado del Río Taibilla. Uno de los fines primordiales del organismo era garantizar el abastecimiento de Cartagena y su Base Naval, si bien, el proyecto definitivo extendía el área de suministro a Murcia, Campo de Lorca, Vegas del Segura y Alicante, que no tenían entonces otra posibilidad de abastecimiento, lo que obligó a incorporar nuevas fuentes de suministro de la cuenca del Segura y, sobre todo, a partir de 1979, del trasvase Tajo-Segura (Morales Gil, A. 2002). El promedio de agua trasvasada desde 1979 a 2005 asciende a $340 \mathrm{hm}^{3} /$ año, de los cuales una tercera parte se destina a los abastecimientos de agua potable. Este volumen representa alrededor del $60 \%$ de los recursos de agua que distribuye la Mancomunidad de Canales del Taibilla a más de 2.500.000 habitantes de las regiones de Murcia, Castilla-La Mancha y Comunidad Valenciana. De los 79 municipios que atiende, 35 corresponden a las comarcas alicantinas del Bajo Segura, Bajo Vinalopó, Campo de Alicante y Marina Baja. El fuerte incremento del consumo por la expansión de nuevas áreas urbanas y turísticas, planteó una creciente competencia de usos por las aguas del trasvase. Así, en 1986 el trasvase Tajo-Segura aportó a la Mancomunidad de Canales del Taibilla (MCT) un total de 106'55 hm³ , es decir, un

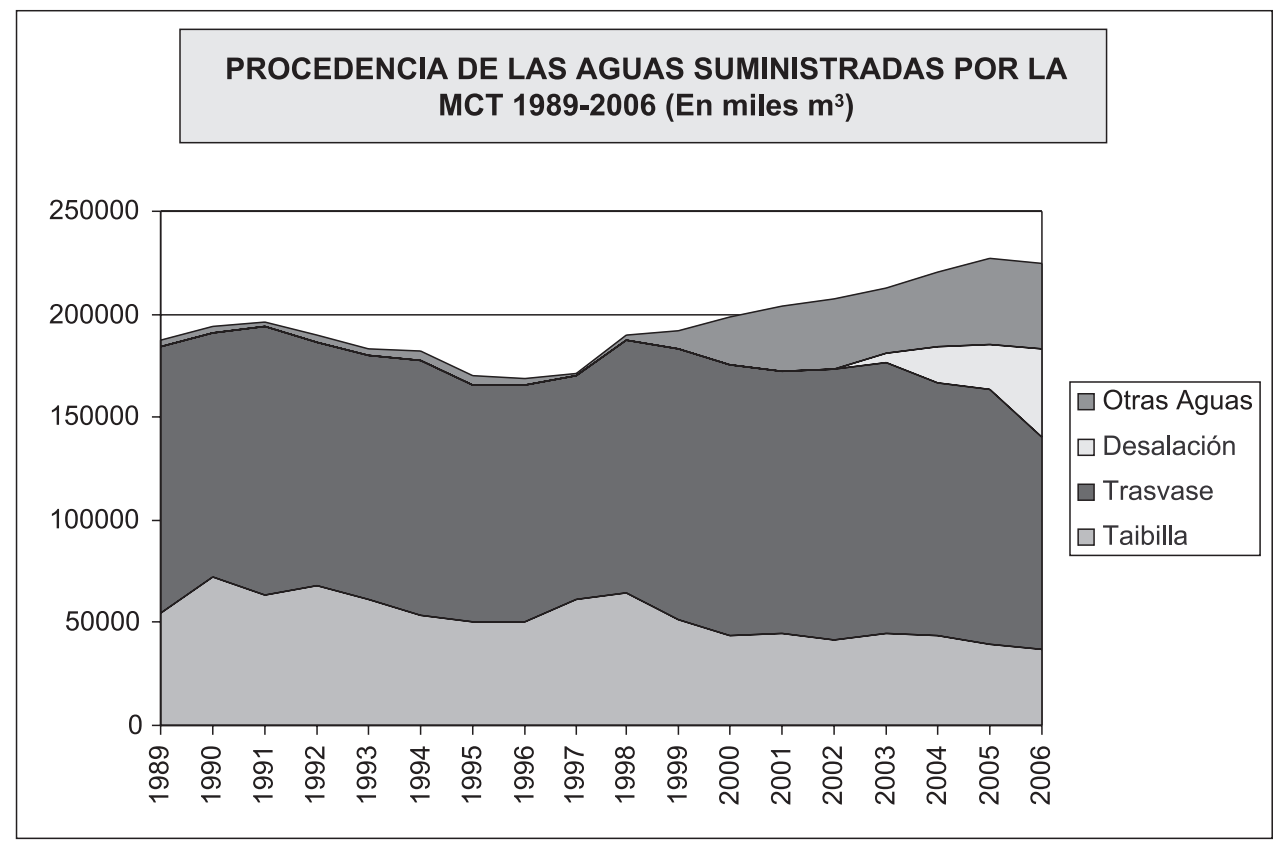


volumen que representaba casi el límite de la dotación prevista por el trasvase para suministro urbano en su primera fase, que se había cifrado en $110 \mathrm{hm}^{3} /$ año. En 1988, con el fuerte ritmo de expansión urbanística de los municipios costeros, se superó la dotación teórica mencionada. La situación se vería más agravada aún por el descenso advertido, el año 1987, en las aportaciones del río Taibilla, que disminuirían todavía más en los primeros años del siglo XXI, de forma que en 2004 tan sólo pudo aportar 43,2 hm³, frente a los 70 $\mathrm{hm}^{3}$ que debería proporcionar como promedio.

Además, esa disminución cobra más importancia si se tiene en cuenta que el consumo de la Mancomunidad experimentó un incremento superior al $10 \%$ en dicho periodo, al crecer de los $198 \mathrm{hm}^{3}$, de 2000, a los $227 \mathrm{hm}^{3}$ en 2005 y $225 \mathrm{hm}^{3}$ en 2006 . Este último año, además de la contribución del exangüe Taibilla, que sumó $37 \mathrm{hm}^{3}$, el trasvase Tajo-Segura aportó $103 \mathrm{hm}^{3}$ y las cuencas del Segura y Júcar otros $42 \mathrm{hm}^{3}$, que se completaron con 41 $\mathrm{hm}^{3}$ obtenidos en las desaladoras del Canal de Alicante y San Pedro del Pinatar (Murcia). Antes de la derogación del trasvase del Ebro y de la promulgación del Programa A.G.U.A., el Ministerio de Medio Ambiente había previsto el desarrollo de un plan de desalación para garantizar el suministro de la Mancomunidad de los Canales del Taibilla, que se basaba en la construcción de 4 plantas desaladoras, que aportarían unos $80 \mathrm{hm} /$ año. Con ello, se quiere garantizar el consumo de agua potable de 79 municipios y una población que supera ya los 2.500.000 habitantes, y se eleva otro millón más en verano, por el efecto estacional del turismo. Fruto de este plan, la desaladora de Alicante inaugurada en el verano de 2003 y la de San Pedro del Pinatar, en 2005, aportan en torno de $48 \mathrm{hm}^{3} /$ año. Se había previsto para 2007 alcanzar una capacidad de desalación de 80 hm³/año, con la ampliación de las plantas citadas y la construcción de otra nueva en el Campo de Cartagena (Valdelentisco). Con el Programa A.G.U.A. (Real Decreto Ley 2/2004, de 18 de junio), el Ministerio de Medio Ambiente ha previsto incrementar todavía más la participación de las desaladoras en el suministro de agua potable de la Mancomunidad, con una capacidad de producción que alcanzaría en 2008 un volumen de 146 hm²/año. La introducción de aguas desaladas ha tenido ya repercusiones notorias sobre las tarifas, que se han elevado un $23 \%$, y se ha estimado que durante los próximos años la factura del agua potable distribuida en alta por la Mancomunidad se incrementará más del $60 \%$ cuando se complete el Programa A.G.U.A. Así, el precio del agua que suministra la Mancomunidad a los ayuntamientos crecerá de 31,13 céntimos de euro en 2005 a 51,14 céntimos en 2008 .

La expansión de áreas urbano-turísticas durante las dos últimas décadas se ha dejado sentir en las dinámicas de evolución del consumo, con un fuerte aumento en el gasto de agua servida en alta, desde el año $1984\left(131,2 \mathrm{hm}^{3}\right)$ a $1991\left(191,3 \mathrm{hm}^{3}\right)$ y $2006\left(225 \mathrm{hm}^{3}\right)$. No obstante, dentro de esa serie de años, 1991 significó una inflexión en el crecimiento del consumo, debido a los efectos de la sequía de la primera mitad de los noventa, que propició una reducción del consumo, hasta un mínimo de 167 hm³ en 1996. Las mejoras técnicas introducidas durante esos años en la gestión en baja dentro de las ciudades para incrementar el control del agua no registrada, motivaron un gran ahorro de agua potable, que sirvió para atender las demandas de las nuevas áreas urbanas. A medida que se agotaban las posibilidades de ahorro de agua en la distribución en baja, la expansión de nuevas zonas residenciales favoreció un segundo ciclo de expansión del consumo a partir de 1997 $\left(168 \mathrm{hm}^{3}\right)$, que ha continuado hasta $2006\left(225 \mathrm{hm}^{3}\right)$.

La capital de la provincia incrementó su consumo de agua de $19,3 \mathrm{hm}^{3}$ en 1984 a 24,6 $\mathrm{hm}^{3}$ en 1991, para descender a menos de $19 \mathrm{hm}^{3}$ en 1995, y volver a recuperarse a partir de entonces para superar los $25 \mathrm{hm}^{3}$ en 2006, si bien, incorporando en este caso el consumo de agua de San Vicente del Raspeig que supuso para ese año, un volumen de 3,4 hm $\mathrm{hm}^{3}$ Latra gran ciudad valenciana que depende de la MCT es Elche y su aglomeración, que necesitó 
en 2006 un volumen de $16,4 \mathrm{hm}^{3}$ de suministro de agua en alta, de los cuales unos 14,6 $\mathrm{hm}^{3}$ fueron facilitados por la MCT y el resto $\left(1,8 \mathrm{hm}^{3}\right)$ de pozos situados en Villena. Estos datos confirman que Elche ha duplicado, prácticamente, el consumo de agua procedente del Taibilla, en comparación con 1984, cuando necesitó de la MCT el suministro de 7,4 $\mathrm{hm}^{3}$. Una progresión similar ha tenido Santa Pola, que ha incrementado el consumo de agua potable de $2,3 \mathrm{hm}^{3}$, en 1984 , a $3,9 \mathrm{hm}^{3}$, en 2006 .

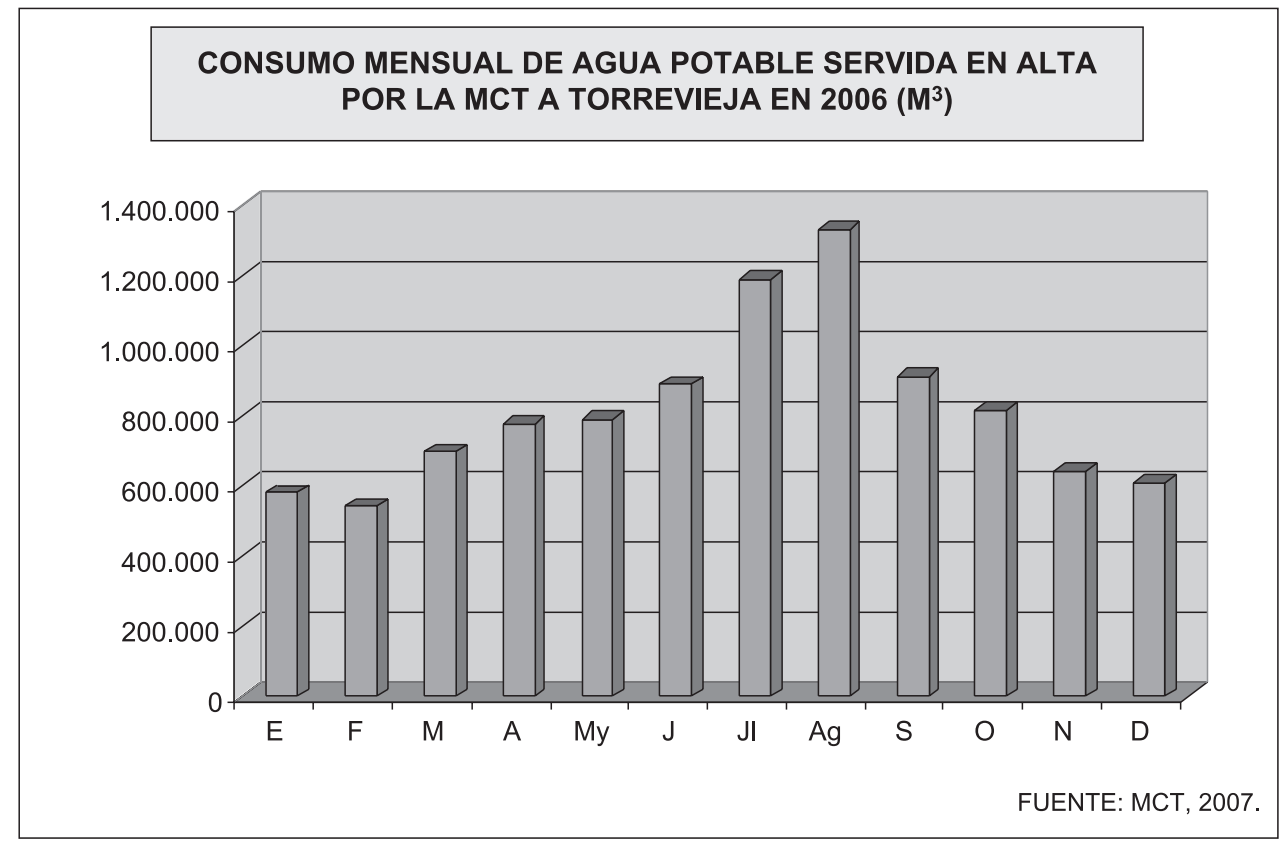

Otro de los ejemplos llamativos corresponde a Torrevieja, que ha incrementado el consumo de agua en alta de 6,2 $\mathrm{hm}^{3}$ en 1994, a 10,3 $\mathrm{hm}^{3}$ en 2001, y lo ha reducido en 2006 a $9,7 \mathrm{hm}^{3}$ a gracias a los avances experimentados en la gestión en baja, con un rendimiento que supera el $85 \%$ sobre caudal suministrado a la red. Este municipio se ha caracterizado tanto por la extensión del hábitat turístico-residencial (más de 2.500 ha de suelo urbano) como por las elevadas densidades y ocupación estacional. Las más de 240.000 plazas en viviendas y apartamentos de uso no principal, junto con una reducida y muy poco representativa planta hotelera (alrededor de 1.700 plazas), contribuyen a una ocupación que supera los 400.000 habitantes en momentos punta del mes de agosto, mientras que se reduce de forma notable en temporada baja (Vera Rebollo, J.F., 2002) ${ }^{2}$.

La Mancomunidad de los Canales del Taibilla ha realizado diversos estudios de prospectiva sobre las tendencias de consumo de agua potable en el área que atiende, a partir de variables de planeamiento, de construcción de vivienda y de dinámicas demográficas, estimando que en el horizonte del año 2025 la demanda superará los $320 \mathrm{hm}^{3} / \mathrm{año}$. Este incremento del consumo de agua potable vendrá motivado por la construcción de 682.000

2 Durante el periodo 1996-2001, el municipio de Torrevieja ocupó el segundo lugar de España, tras Madrid y por delante de Barcelona, por el número total de certificaciones de fin de obra de viviendas, con 33.349 unidades construidas. 
nuevas viviendas, destinadas a vivienda principal (428.000 unidades) y segunda residencia (254.000). Así, en 2025, a pesar de que la dotación bruta por vivienda descenderá de 439 a 421 litros/vivienda/día por la mayor eficiencia de la gestión, la Mancomunidad estaría obligada a incrementar las fuentes actuales de suministro en más de $100 \mathrm{hm}^{3} / a$ ño.

Además de la Mancomunidad de los Canales del Taibilla, en territorio del sistema de explotación Vinalopó-L'Alacantí existen otras entidades con lugar destacado en la distribución de agua potable, en especial la empresa mixta Aguas Municipalizadas de Alicante donde participan el Ayuntamiento de Alicante y AQUAGEST (Aguas de Barcelona), que gestiona parte del suministro de agua potable servida en alta yen baja a la capital y su área metropolitana. En concreto, para la comarca del Campo de Alicante, se precisan alrededor de $45 \mathrm{hm}^{3} /$ año para atender una población que, durante el verano, puede superar los 600.000 habitantes, con módulos personales de gasto que no suelen superar los 180 1/habitante/día, y rendimientos que, en el caso de la capital provincial, superan el $90 \%$ del caudal inyectado en la red. A los recursos que le facilita la Mancomunidad de los Canales del Taibilla se suman las aguas subterráneas de varios acuíferos del Alto Vinalopó, que son aprovechados por la capital provincial desde 1898.

Otra de las entidades modélicas en la gestión del agua potable en municipios turísticos valencianos es el Consorcio de Aguas de la Marina Baixa, creado en 1977, al amparo de la Ley de Bases de Régimen local, y que agrupa a ocho municipios, entre los que se encuentra Benidorm. Dicho organismo ha hecho frente al fuerte incremento del consumo de las dos últimas décadas, que ha pasado de $9 \mathrm{hm}^{3}$ en 1980 a $22 \mathrm{hm}^{3}$ en 2004. Es de notar la grave situación que padeció Benidorm en septiembre de 1978, cuando hubo de ser abastecida con buques cisterna desde la ciudad de Alicante y utilizar, incluso, aguas subterráneas con alto grado de salinidad procedentes de pozos de emergencia perforados en los mismos sótanos de hoteles y apartamentos. A raíz de este suceso, la imagen turística de Benidorm sufrió serio deterioro ocasional, al punto de perder el turismo de procedencia

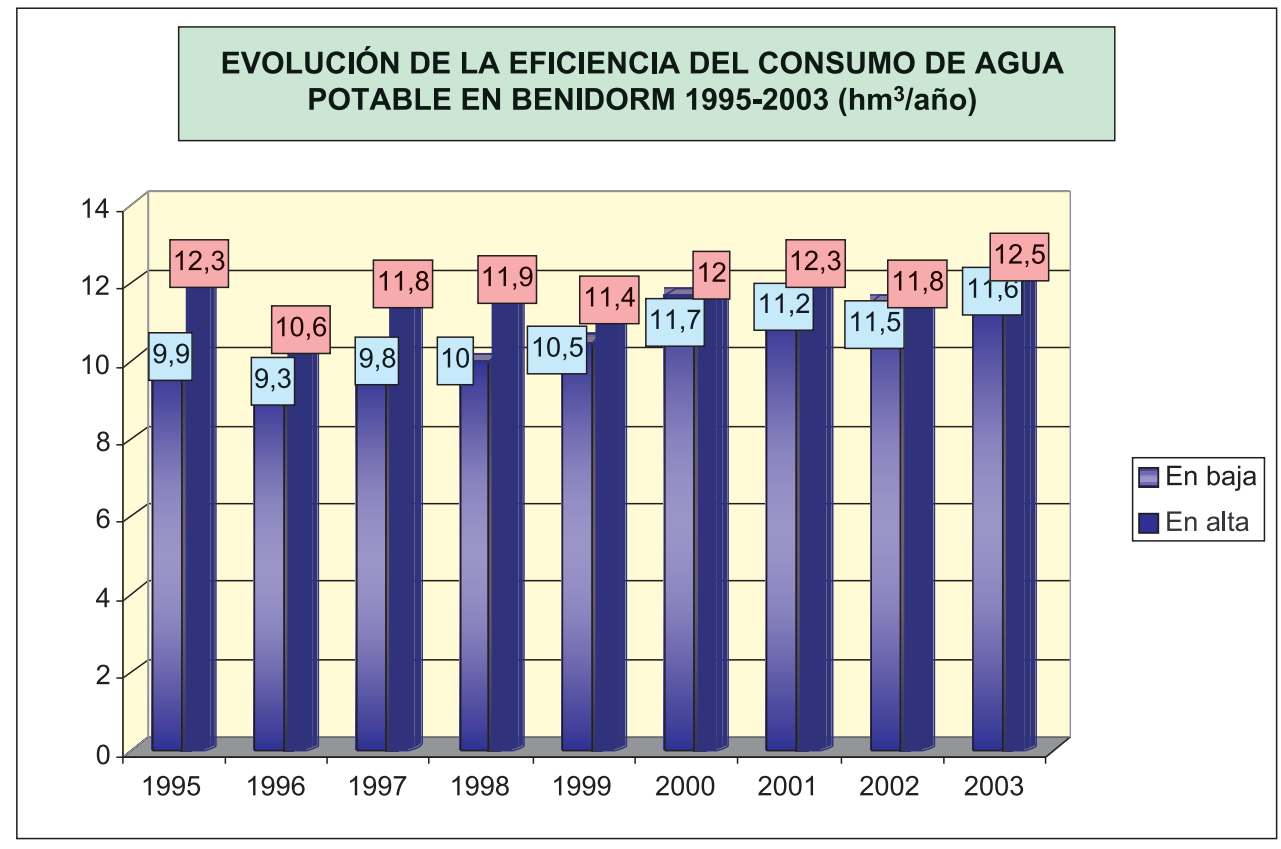


alemana, que desde entonces no ha recuperado. En la actualidad, el Consorcio de Aguas de la Marina Baja garantiza la distribución en alta a 7 municipios, entre ellos Benidorm, que suman una población de 160.000 habitantes, que puede superar los 600.000 en verano. El consumo se ha estabilizado durante los últimos años en unos $22 \mathrm{hm} / 3 / \mathrm{año}, 12 \mathrm{de}$ ellos para Benidorm, gracias a la excelente gestión de la demanda por el Consorcio y la empresa Aquagest, que se hace cargo de la distribución en baja dentro de la ciudad. Todo el sistema descansa en un complejo hidráulico modélico que permite el aprovechamiento integral de recursos superficiales y subterráneos, aguas residuales depuradas con terciario y trasvases. Las captaciones y la red de distribución, con $103 \mathrm{~km}$ de recorrido, se gestionan mediante un sofisticado sistema de telecontrol y SIG. Otra estrategia fundamental del Consorcio es el establecimiento de diferentes acuerdos con los regantes para la cesión de aguas limpias a cambio de residuales depuradas y de otras compensaciones económicas en infraestructuras agrarias.

Estos acuerdos permiten acceder a las aguas subterráneas de los pozos Algar-Sacos, que aprovecha la Comunidad General de Regantes de Callosa d'En Sarriá a cambio de diferentes compensaciones en infraestructura y fluido eléctrico, que pueden elevarse a más de 600.000 $€$ anuales. También se dispone de los campos de bombeo existentes en Beniardá, Polop y Sella, que se suman a los recursos superficiales de los embalses de Guadalest y Amadorio, con $26 \mathrm{hm}^{3}$ de capacidad global. En junio de 2006 se inauguró el sistema terciario de la depuradora de Benidorm, que incluye la desalación del agua residual mediante sistema de ósmosis inversa, con capacidad de $25.000 \mathrm{~m}^{3} /$ día para 2.000 ha de regadíos en el Canal Bajo del Algar y riego de parques, jardines y baldeo de calles en las zonas residenciales de la comarca.

La multiplicación de apartamentos y residencias secundarias diversas convierte a la oferta extrahotelera en la más abundante, al estimarse la existencia de unos 2 millones de plazas frente a las 120.000 plazas en hoteles. Los consumos de agua propiciados por la oferta de alojamiento hotelera son exiguos y globalmente poco importantes. Con datos de facturación, se puede evaluar el consumo de agua en establecimientos hoteleros según su categoría. En los de una estrella, el promedio de gasto de agua por turista alojado no llega

\section{REPERCUSIÓN DEL POBLAMIENTO URBANO-TURÍSTICO SOBRE EL CONSUMO DE AGUA POTABLE EN MODELOS DE CIUDAD COMPACTA TIPO «BENIDORM»}

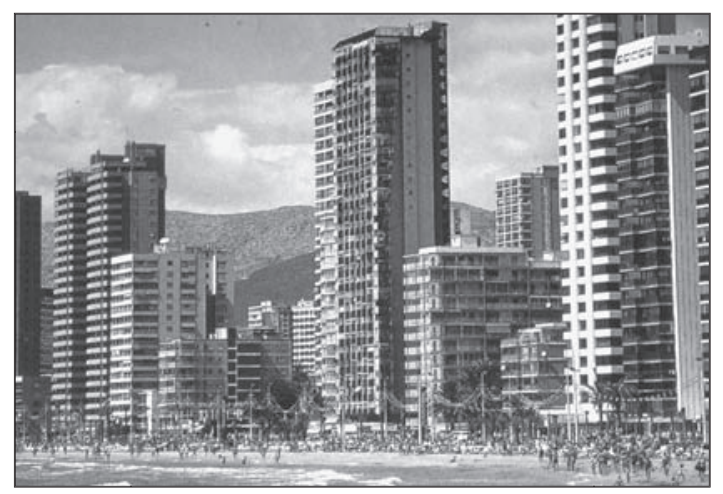

- La ciudad compacta permite una gestión más eficiente del ciclo integral del agua.

- Disminuye la longitud de las redes, se agilizan tareas de localización y reparación de fugas mediante SIG y sectorización de la red.

- Disminuyen las pérdidas en la red litros/ km.día

- Se reducen los volúmenes de Agua No Registrada (ANR).

- Los módulos de gasto por turista no suelen superar los 200 litros/hab/día

- Se reduce la estacionalidad y se mantiene una oferta hotelera activada gran parte del año. 
a 175 litros/día, mientras que en los hoteles de categorías superiores, dotados de piscina, los módulos de consumo personal alcanzan valores de 194 litros/día, y de 287 litro/días en los de dos y tres estrellas, respectivamente. Son módulos de gasto moderados, que incluyen todos los servicios prestados por los hoteles en lavandería, restaurante o la propia piscina. Con estos datos, proporcionados por las facturas del agua potable, se puede estimar que toda las oferta de alojamiento hotelera existente en la Comunidad Valenciana podría generar un consumo no superior a $10 \mathrm{hm}^{3} / \mathrm{año}$.

Uno de los municipios que concentra la oferta de alojamiento turística más importante de la Comunidad Valenciana, el de Benidorm, ha precisado durante los últimos años 12 $\mathrm{hm}^{3} /$ año para satisfacer, entre otras demandas, las necesidades de 142 establecimientos hoteleros, con capacidad de alojamiento que supera las 36.000 plazas. Esta oferta está activada durante gran parte del año, con una capacidad para generar unos ingresos que, por término medio, pueden superar los 60 euros/día por turista alojado. Así, con un nivel medio de ocupación anual que ronda el $92 \%$, los turistas, con fuerte presencia de extranjeros, que eligen como destino Benidorm, aportan a la economía de esta localidad con unos ingresos que, según estimaciones, pueden ascender a más de 500 millones de euros. A ello se une la elevada capacidad de creación de empleo en este tipo de municipios, a los que acompaña una abundante oferta complementaria de ocio, restauración y comercio. Además de los 142 establecimientos hoteleros con más de 36.000 plazas -a las que se sumarán otras 5.000 en los próximos años - , la ciudad dispone de unos 370 restaurantes, mas de 250 cafeterías y 2.200 comercios. Con algo mas de 50.000 habitantes empadronados, en claro contraste con los 6.000 con que contaba la población marinera a principios de los años sesenta, esta ciudad de ocio recibe anualmente cientos de miles de visitantes, que generan mas de 10 millones de pernoctaciones, sólo en establecimientos hoteleros (Vera, J.F., 2002).

El modelo urbano concentrado de Benidorm surgió de un instrumento pionero de planeamiento urbanístico, que estableció la creación de dos ensanches, a Levante y Poniente, además de una zona de expansión del núcleo convencional, de modo que las altas densidades y la edificación en altura son las notas mas características, como contrapunto a la diseminación del hábitat tan al uso en muchos municipios costeros de Alicante. La concentración de la edificación rentabiliza de manera más eficiente las infraestructuras hidráulicas de distribución de agua potable y saneamiento, a la vez que el modelo de oferta de apartamentos y hoteles justifica una utilización intensiva del espacio urbano-turístico y contribuye a explicar la menor estacionalidad, frente al resto de destinos litorales.

Dentro de las demandas urbano-turísticas también debe contabilizarse el consumo de agua propiciado por la población estacional asociada a la oferta extrahotelera durante el verano y periodos de vacaciones. Los sistemas de abastecimiento se ven obligados a atender las demandas de los más de 2.000.000 habitantes que acuden a núcleos de veraneo como Torrevieja, Santa Pola, la misma Benidorm, Denia o Calpe en la provincia de Alicante; los municipios de Cullera, Gandia, Sueca, Sagunto, Pobla de Farnals y Oliva en la de Valencia; Benicásim, Peñíscola, Alcalá de Chivert, Benicarló y Vinaroz en la provincia de Castellón. Un rasgo característico de los abastecimientos en estos núcleos de veraneo es la estacionalidad del consumo, que se intensifica durante los meses de julio y agosto. Es frecuente que estos meses tripliquen los consumos de invierno, hecho que obliga a dimensionar los sistemas de abastecimiento de agua potable y de depuración. Ello sucede en núcleos como Santa Pola, Denia, Jávea, Alfaz del Pí, lo que genera problemas para garantizar los abastecimientos de agua. En estos municipios la mayoría de los indicadores de presión del agua ofrecen valoraciones negativas, propiciadas en gran medida por el acusado consumo estacional de agua, si bien, desde mediados de los años noventa del siglo pasado se esta 
evidenciando una «desestacionalidad» en los principales destinos vacacionales, al ampliarse los periodos de estancia, la residencia permanente o la oferta de alojamiento hotelera. Así se ha constatado en municipios del litoral sur de Alicante como Guardamar del Segura, donde la estacionalidad pasa de 3,85 en 1991, a 3,48 en 2000; en Pilar de la Horadada, se reduce de 3,55 a 2,28 y en Torrevieja de 3,37 a 3,10 (Juárez Sánchez- Rubio, C. 2004).

\section{REPERCUSIÓN DEL POBLAMIENTO URBANO-TURÍSTICO SOBRE EL CONSUMO DE AGUA POTABLE EN MODELOS DE CIUDAD DIFUSA}

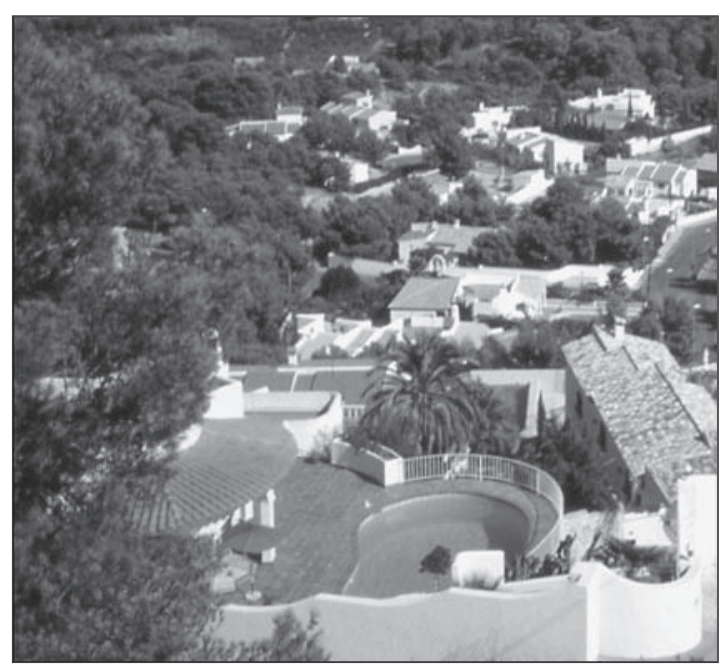

- La ciudad difusa y de baja densidad propicia un mayor consumo de suelo y de recursos hídricos.

- La mayor longitud de las redes de distribución incrementa las pérdidas en la red litros/km.día.

- Crece el volumen de Agua No Registrada (ANR) y se hace más difícil la detección de fugas.

- Los sistemas de captación, distribución, saneamiento y depuración deben dimensionarse para atender la estacionalidad.

- En viviendas unifamiliares con jardín y piscina se alcanzan módulos de 600 1/hab/día y el consumo se intensifica en verano.

- Esta oferta de alojamiento se activa sobre todo en verano y vacaciones. Menor trascendencia socioeconómica del uso del agua.

Si se trata de viviendas unifamiliares con piscina privada y jardín, se pueden alcanzar a veces módulos personales de más de 600 l/habitante/día. No obstante, el poblamiento estacional característico de núcleos de veraneo como Benicasim, Cullera o Torrevieja, consiste en bloques de apartamentos y viviendas unifamiliares en adosados, sin jardín ni piscina. En estas unidades de consumo, cuando se encuentran ocupadas, los módulos personales de gasto oscilan entre 150 y 200 litros/habitante/día. Debe tenerse en cuenta que este tipo de demanda se activa durante el verano y periodos de vacaciones, y que la ocupación de estas viviendas no supera los 90 días. Considerando estas variables, y la existencia de unos 2 millones de plazas, se puede estimar que el consumo de agua potable de la oferta de alojamiento extrahotelera en la Comunidad Valenciana no pasaría de los $40 \mathrm{hm}^{3} / \mathrm{año}$. Si a estos consumos se suman los recursos necesarios para atender la oferta hotelera (10 hm³ $/$ año $)$, la de campos de golf ( $11 \mathrm{hm}^{3} /$ año), más la generada por otras instalaciones y equipamientos de ocio como parques acuáticos, se puede estimar que la demanda turística de la Comunidad Valenciana estaría cercana a $80 \mathrm{hm}^{3} /$ año. Si se tiene en cuenta que las demandas consuntivas de la región ascienden a $3.432 \mathrm{hm}^{3} /$ año, las turísticas apenas representan el 2,3\% del total, mientras que las agrarias $\left(2.703 \mathrm{hm}^{3} /\right.$ año $)$ representan el 78,7 \%. Sin embargo, esta participación relativa del turismo podría elevarse a valores entre el 5 y el $6 \%$ del total de la demanda, si se incluye el abastecimiento a poblaciones cuya especialización funcional se relaciona directamente con la actividad turística. 


\section{El comportamiento de las demandas urbano-turísticas a partir de las unidades de consumo vinculadas con la actividad}

Se ha hecho notar la dificultad que entraña desglosar el gasto de agua propiamente turístico dentro de los abastecimientos urbanos, ya que las redes de distribución ofrecen cobertura indistintamente a viviendas permanentes, industrias, usos públicos y a unidades de consumo relacionadas con la actividad turística, entre las cuales puede tener cabida oferta de alojamiento hotelera y extrahotelera, en muchos casos no reglada. Para llevar a cabo un análisis sobre la relación entre el turismo y el consumo de agua resulta imprescindible distinguir entre las diversas tipologías de poblamiento turístico. Así, debe advertirse que los niveles de consumo, de pérdidas y, en última instancia, la rentabilidad económica del agua son distintos en un municipio caracterizado por una presencia elevada de instalaciones hoteleras muy concentradas en el territorio y en otro en el que el turismo se manifiesta a través de su modalidad residencial, con un patrón de gran ocupación del territorio mediante urbanizaciones con viviendas en baja densidad. En el caso valenciano la expansión del poblamiento urbano-turístico ha estado condicionada por las exigencias de unos visitantes que demandan los productos asociados al disfrute del clima, del mar y de las playas en sus diferentes modalidades (Vera Rebollo, J.F. 2002):

a) grandes centros de turismo de sol y playa con abundante oferta hotelera y complementaria, entre los cuales destaca Benidorm, que concentra el $42 \%$ de las plazas disponibles en hoteles de la Comunidad Valenciana.

b) espacios urbanos vacacionales y de segunda residencia, entre los cuales se hallan Torrevieja, Peñíscola, Benicasim, Gandía, Cullera o Denia.

c) áreas urbanas de media y baja densidad destinadas a residentes extranjeros, como las implantadas en Teulada, Calpe, Benisa o Alfaz del Pí.

Con la información facilitada por las empresas y los ayuntamientos que gestionan los servicios de abastecimiento de agua potable se puede alcanzar un conocimiento bastante preciso del gasto que generan las diferentes unidades de consumo relacionadas con la actividad turística. En este sentido, cabe distinguir las unidades de gasto asociadas al tipo de alojamiento (hotelero y extrahotelero) y las relativas a la oferta complementaria (restaurantes, parques temáticos, etc). En ambos casos, hay una serie de variables que resultan decisivas en el consumo de agua potable, particularmente las que se refieren al consumo de espacio y tiempo, a la duración de las estancias y al tipo de alojamiento demandado por los turistas en los destinos turísticos que visitan. El modelo turístico de «sol y playa» ha favorecido tipologías de poblamiento que se caracterizan por una fuerte estacionalidad, si bien, durante la última década se ha constatado una reducción de la misma, sobre todo en el turismo extranjero procedente de Europa occidental que ha aumentado de forma notoria la adquisición de viviendas residenciales. Este incremento del llamado «turismo residencial» favorece una estancia mucho mayor de los turistas, hasta convertirse en población permanente que demanda un suministro regular de agua potable y, la mayoría de las veces, con un alto módulo personal, ya que suelen adquirir viviendas unifamilares con jardín y con piscina. En cambio, durante los últimos años se ha detectado una disminución de las pernoctaciones por turista en oferta hotelera, que sigue siendo la modalidad de alojamiento preferida por el $70 \%$ de los turistas extranjeros que vienen a España. El $20 \%$ se alojaría en vivienda gratuita, ya sea propia o de un familiar, y el $9 \%$ en vivienda alquilada. El turista extranjero alojado en hoteles, suele venir en grupos pequeños, de 3 a 5 personas, tiene una estancia media de 8 días, puede pagar por el paquete turístico alrededor de unos 
500 euros en temporada alta, y unos 300 en temporada baja. Además de este paquete, gasta en destino unos 60 euros/día o más. En cambio, el turista extranjero que se aloja en una vivienda gratuita, suele ocupar ese alojamiento más de 2 semanas y es menor su capacidad de gasto económico. El turista español que opta por la oferta hotelera suele alojarse menos de 4 noches y su gasto económico se sitúa alrededor de los 40 euros día.

\section{Cuadro ${ }^{\circ} 4$}

RASGOS BÁSICOS DE LA DEMANDA TURÍSTICA Y REPERCUSIONES SOBRE LOS DESTINOS DE LA COMUNIDAD VALENCIANA

\begin{tabular}{|c|c|c|c|}
\hline VARIABLE & TURISTAS & VERANEANTES & RESIDENTES \\
\hline $\begin{array}{l}\text { Duración de la } \\
\text { estancia }\end{array}$ & $\begin{array}{l}\text { Menos de } 2 \\
\text { semanas } \\
\text { Extranjeros: } 8 \\
\text { días en hotel. } \\
\text { Nacionales: } 4 \text { días } \\
\text { en hotel. } \\
\text { En turismo rural } \\
3 \text { días }\end{array}$ & $\begin{array}{l}\text { De } 2 \text { semanas a } 3 \text { meses. } \\
\text { En apartamentos } \\
\text { turísticos: } 12 \text { días. }\end{array}$ & $\begin{array}{l}\text { Más de } 2 \text { meses. } \\
\text { Tendencia creciente } \\
\text { a prolongar } \\
\text { residencia de } 6 \text { a } 8 \\
\text { meses o más. }\end{array}$ \\
\hline $\begin{array}{l}\text { Tipo de } \\
\text { Alojamiento }\end{array}$ & $\begin{array}{l}\text { Preferentemente } \\
\text { en hoteles y } \\
\text { en viviendas } \\
\text { en alquiler } \\
\text { (apartamentos) }\end{array}$ & $\begin{array}{l}\text { Viviendas en propiedad o } \\
\text { alquiladas. Apartamentos } \\
\text { y unifamiliares }\end{array}$ & $\begin{array}{l}\text { Viviendas en } \\
\text { propiedad, } \\
\text { principalmente } \\
\text { unifamiliares. }\end{array}$ \\
\hline $\begin{array}{l}\text { Composición } \\
\text { del grupo }\end{array}$ & De 3 a 5 personas. & De 3 a 4 personas. & $\begin{array}{l}\text { Inferior a } 3 \\
\text { personas. }\end{array}$ \\
\hline $\begin{array}{l}\text { Gasto } \\
\text { económico }\end{array}$ & $\begin{array}{l}\text { Fuerte, más de } 60 \\
\text { euros. }\end{array}$ & $\begin{array}{l}\text { Moderado, de } 25 \text { a } 35 \\
\text { euros. }\end{array}$ & $\begin{array}{l}\text { Débil a moderado, } \\
\text { de } 20 \text { a } 30 \text { euros. } \\
\text { Pautas de consumo } \\
\text { convencionales. }\end{array}$ \\
\hline $\begin{array}{l}\text { Tipo de } \\
\text { poblamiento }\end{array}$ & $\begin{array}{l}\text { Modelos urbanos } \\
\text { de alta densidad. } \\
\text { Gran dinamismo } \\
\text { servicios de } \\
\text { ocio, recreación } \\
\text { y oferta } \\
\text { complementaria. }\end{array}$ & $\begin{array}{l}\text { Modelos urbanos } \\
\text { de media densidad } \\
\text { con tendencia a la } \\
\text { compactación. } \\
\text { Desarrollo de potentes } \\
\text { áreas comerciales de } \\
\text { influencia comarcal } \\
\text { (Torrevieja) }\end{array}$ & $\begin{array}{l}\text { Modelos urbanos } \\
\text { con urbanizaciones } \\
\text { de baja densidad. } \\
\text { Creciente } \\
\text { ocupación de } \\
\text { municipios del } \\
\text { interior de base } \\
\text { rural. }\end{array}$ \\
\hline $\begin{array}{l}\text { Estacionalidad } \\
\text { de la } \\
\text { ocupación }\end{array}$ & $\begin{array}{l}\text { Buen nivel } \\
\text { de ocupación } \\
\text { durante todo el } \\
\text { año (Benidorm) } \\
\text { y menor en otros } \\
\text { destinos. }\end{array}$ & $\begin{array}{l}\text { Mayor ocupación en } \\
\text { verano y periodos de } \\
\text { vacaciones. } \\
\text { Aumento de la } \\
\text { estancia. Tendencia a la } \\
\text { «desestacionalización». }\end{array}$ & $\begin{array}{l}\text { Ocupación estable } \\
\text { durante todo el } \\
\text { año, con ligera } \\
\text { disminución en los } \\
\text { meses anteriores al } \\
\text { verano. }\end{array}$ \\
\hline
\end{tabular}

Fuente: Elaboración propia a partir de Vera Rebollo, J.F. y Baños Castiñeira, C. (2001); Iribas Sánchez, J.M. (1995) y EGATUR (2006). 
La oferta de alojamiento más abundante en territorio valenciano es la no comercial, es decir, la extrahotelera o de alojamiento residencial (viviendas unifamiliares y bloques de apartamentos) que puede superar los 2 millones de plazas. En los municipios en que predomina este tipo de oferta, la actividad turística se halla fuertemente condicionada por la estacionalidad en la afluencia de visitantes, con estancias prolongadas (hasta 90 días en verano), en viviendas alquiladas o propias, con grupos superiores a 3 personas, y con una capacidad de gasto económico que no suele superar los 25 euros. A tenor de estas características, lo cierto es que en todo el litoral de la Comunidad Valenciana tan sólo el municipio de Benidorm puede ser adscrito a la categoría de turístico en sentido estricto, con un modelo urbanístico de alta densidad, abundante oferta hotelera y de servicios complementarios, gran dinamismo empresarial, y una incalculable capacidad para generar rentas económicas y demandar mano de obra. Este tipo de modelo urbanístico es muy eficiente en la gestión de recursos de agua, al disponer de diseños técnicos adecuados y estar afectado de una menor estacionalidad en el consumo de agua potable. Con datos de facturación de agua, combinados con datos de capacidad de alojamiento y de ocupación, se puede valorar el comportamiento que reflejan las diferentes unidades de consumo relacionadas con la actividad turística. En este caso, con la colaboración de la empresa Aquagest, concesionaria del servicio de agua potable de Benidorm, se accedió a datos de facturación del periodo 2001-2003, de diferentes unidades de consumo. En este municipio, se disponía en 2002 de una oferta de alojamiento en hoteles, apartamentos reglados, campings y vivienda no reglada que se aproximaba a 170.000 plazas. La de hoteles sumaba 35.945 plazas, repartida de la siguiente forma: a) los 13 hoteles de 1 estrella sumaban 903 plazas; b) los 33 establecimientos de 2 estrellas otras 6.074 plazas; c) los 58 hoteles de 3 estrellas reunían 19.687 plazas, d) los 21 establecimientos de 4 estrellas sumaban 9.281 plazas.

Los datos de facturación relativos a hoteles de 1 estrella, ofrecen un promedio de consumo anual de $2.808 \mathrm{~m}^{3}$ /año con una media de 74 plazas por establecimiento. En este caso, a diferencia de lo que ocurre con otras categorías de hoteles, esta oferta de alojamiento no está activada durante todo el año, ya que es habitual que se cierre de noviembre a febrero, inclusive. En alguno de estos meses apenas se consume agua, mientras que la máxima actividad se concentra de julio a septiembre, lo que explica que se alcance en este último mes el mayor gasto con $420 \mathrm{~m}^{3} / \mathrm{mes}$. Una variable indicativa de los módulos personales que se alcanzan en esta modalidad de oferta es el consumo medio por plaza ofertada, que alcanza valores medios de 105/litros/plaza/día y, sobre todo, el consumo medio por plaza ocupada, que aumenta a 174 litros/plaza/día. El grado medio de ocupación en este tipo de establecimientos era en 2002 del $71 \%$. Este dato, traducido a plazas ocupadas en relación con las existentes (903 plazas), significaría que unas 641 plazas estarían activadas durante todo el año. El consumo de agua potable efectuado en este tipo de hoteles sería de 111 $\mathrm{m}^{3} /$ día, es decir, 40.709 m³/año. En los establecimientos de 2 estrellas, que sumaban 6.074 plazas, el grado de ocupación media anual crecía al $86 \%$, con un consumo medio anual por establecimiento de $22.494 \mathrm{~m}^{3} /$ año. La menor estacionalidad de la actividad hotelera en esta categoría, explica que el consumo de febrero se eleve a $1.436 \mathrm{~m}^{3} / \mathrm{mes}$, frente a los $2.707 \mathrm{~m}^{3} /$ mes de septiembre. Según los datos de facturación manejados, el consumo medio por plaza ocupada crece a 194 litros/día. Teniendo en cuenta el grado de ocupación (86 \%) y las plazas existentes (6.074), se puede estimar que el consumo de agua potable sería de $1.013 \mathrm{~m}^{3} /$ día ó $369.885 \mathrm{~m}^{3} /$ año. La estacionalidad (sep/feb) se eleva a 1,88 .

Los hoteles de 3 estrellas constituyen la categoría de oferta hotelera más abundante de Benidorm, con 58 establecimientos y 19.687 plazas, que genera una mayor ocupación media anual, con un $88 \%$. En los hoteles analizados, con 322 plazas de oferta media, se alcanza un consumo medio anual de $29.222 \mathrm{~m}^{3} /$ año y mensual de $2.435 \mathrm{~m}^{3} / \mathrm{mes}$. De nuevo, 
es septiembre el mes con mayor consumo, con $3.224 \mathrm{~m}^{3} / \mathrm{mes}$, frente a febrero con 1.917 $\mathrm{m}^{3} / \mathrm{mes}$, lo que traduce una estacionalidad (sep/feb) que se eleva a 1,68. En comparación con el alojamiento hotelero de menor categoría, el consumo medio por plaza ocupada se eleva a 287 litros/plaza ocupada/día. Así, con la ocupación media anual (88 \%) y las plazas existentes se puede estimar un consumo anual de $632.346 \mathrm{~m}^{3} /$ año.

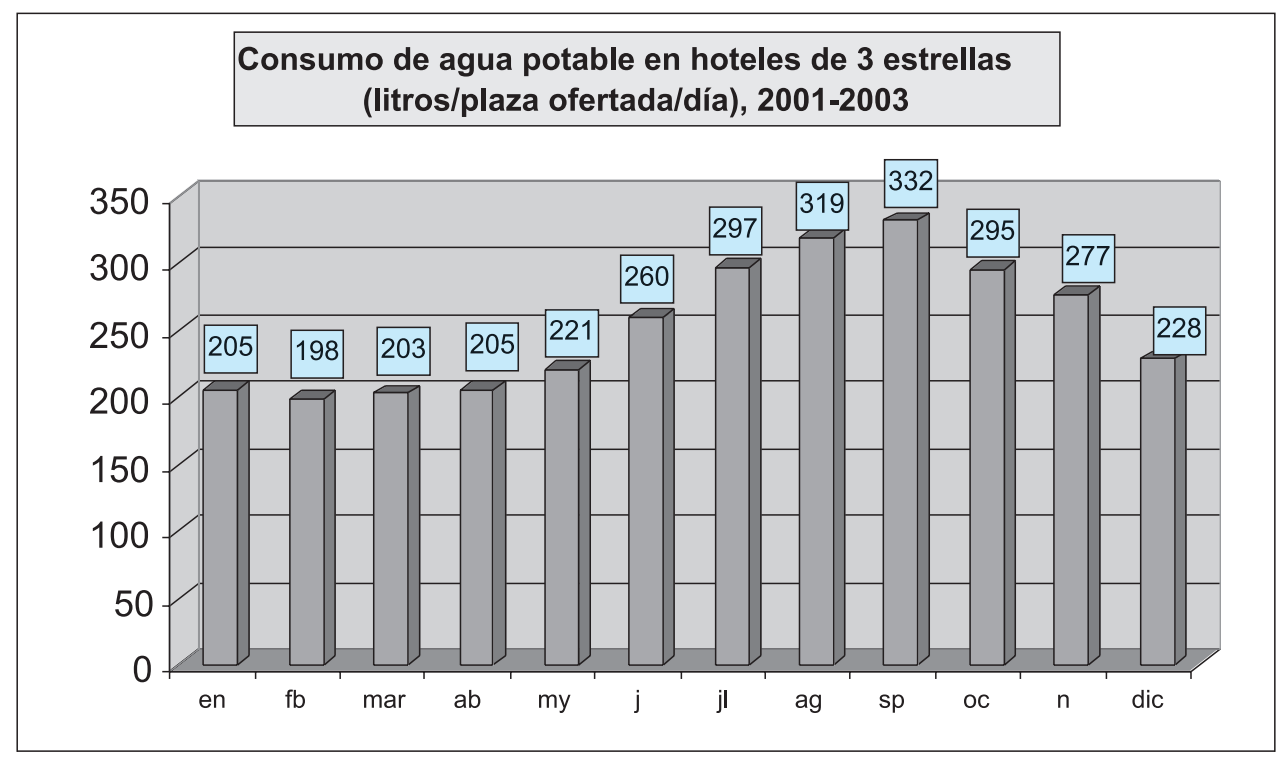

Fuente: Aquagest, 2004.

En la categoría de 4 estrellas, los 21 hoteles existentes en Benidorm generaban una oferta de 9.281 plazas, con una ocupación media del $80 \%$. En los establecimientos analizados, el

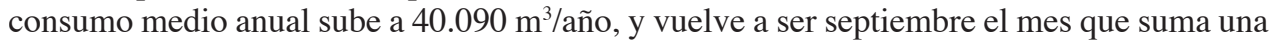
mayor facturación, con $4.812 \mathrm{~m}^{3} / \mathrm{mes}$, frente a febrero con $2.220 \mathrm{~m}^{3} / \mathrm{mes}$. Con estos valores, la estacionalidad (sep/feb) alcanza un valor de 2,16, que resulta superior a las categorías de alojamiento de 2 y 3 estrellas. También es superior el consumo medio por plaza ocupada, que crece a 361 litros/plaza ocupada/día. Por su parte, con la ocupación media anual (80 $\%$ ) y las plazas existentes se puede estimar un consumo anual de $978.328 \mathrm{~m}^{3} /$ año.

Por otro lado, la actividad turística del municipio de Benidorm ha favorecido un fuerte desarrollo de la oferta de alojamiento extrahotelera, principalmente la no reglada. Así, se puede estimar la existencia de una oferta que superaría las 135.000 plazas destinadas a satisfacer una demanda compuesta principalmente por veraneantes que pueden albergarse en vivienda propia o alquilada.

Para valorar este tipo de oferta es también importante comparar el consumo de agua potable que se produce en distintos tipo de viviendas, bien unifamiliares o bien agrupadas en bloques de pisos (Vid. Cuadro ${ }^{\circ}{ }^{6}$ ). En el caso de Benidorm, las llamadas comunidades de propietarios, que en su mayoría corresponden a bloques de pisos, se caracterizan por haber formalizado un contrato colectivo del servicio de agua potable con registro de consumo a través de un único contador. En las comunidades de propietarios en las que domina el poblamiento estacional se alcanzan consumo medios diarios de 252 litros/vivienda/día, si bien, se hace patente el efecto de la estacionalidad $(3,4)$ con máximos de facturación en septiembre, con 460 litros/vivienda/día, y mínimos en enero, con 134 litros/vivienda/día. 


\section{Cuadro $\mathrm{n}^{\circ} 5$}

EL GASTO DE AGUA POTABLE REALIZADO EN ESTABLECIMIENTOS HOTELEROS

DE BENIDORM (2001-2003)

\begin{tabular}{|c|c|}
\hline EST & RASGOS DEL CONSUMO POR ESTABLECIMIENTO \\
\hline $\begin{array}{l}\text { - } 74 \text { plazas de media } \\
\text { - } 56 \% \text { de ocupación } \\
\text { media anual } \\
\text { - } \text { sin piscina }\end{array}$ & $\begin{array}{l}\text { - Consumo medio anual: } 2.808 \mathrm{~m}^{3} / \mathrm{año} \text {. } \\
\text { - Consumo medio mensual: } 217 \mathrm{~m}^{3} / \mathrm{mes} \text {. } \\
\text { - Mes máximo consumo: } \\
\text { o Septiembre: } 420 \mathrm{~m}^{3} / \mathrm{mes} \text {. } \\
\text { - Mes mínimo consumo: } \\
\text { o De noviembre a febrero: } 0 \mathrm{~m}^{3} / \mathrm{mes} \text {. } \\
\text { - Consumo medio por plaza ofertada: } 105 \text { litros/plaza/ } \\
\text { día. } \\
\text { - Consumo medio por plaza ocupada: } 174 \text { litros/plaza/ } \\
\text { día. }\end{array}$ \\
\hline $\begin{array}{l}\text { Hoteles de } 2 \text { Estrellas } \\
\text { - } 320 \text { plazas de media } \\
\text { - } 86 \% \text { de ocupación } \\
\text { media anual } \\
\text { - es habitual la } \\
\text { piscina }\end{array}$ & $\begin{array}{l}\text { - Consumo medio anual: } 22.494 \mathrm{~m}^{3} / \text { año. } \\
\text { - Consumo medio mensual: } 1.874 \mathrm{~m}^{3} / \mathrm{mes} \text {. } \\
\text { - Mes máximo consumo: } \\
\text { o Septiembre: } 2.707 \mathrm{~m}^{3} / \mathrm{mes} \text {. } \\
\text { - Mes mínimo consumo: } \\
\text { o Febrero: } 1.436 \mathrm{~m}^{3} / \mathrm{mes} \text {. } \\
\text { - Consumo medio por plaza ofertada: } 167 \text { litros/plaza/ } \\
\text { día. } \\
\text { - Consumo medio por plaza ocupada: } 194 \text { litros/plaza/ } \\
\text { día. }\end{array}$ \\
\hline $\begin{array}{l}\text { Hoteles } 3 \text { Estrellas } \\
\begin{array}{l}\text { - } 322 \text { plazas de media } \\
\text { - } 88 \% \text { de ocupación } \\
\text { media anual } \\
\text { - con piscina }\end{array}\end{array}$ & $\begin{array}{l}\text { - Consumo medio anual: } 29.222 \mathrm{~m}^{3} / \text { año. } \\
\text { - Consumo medio mensual: } 2.435 \mathrm{~m}^{3} / \mathrm{mes} \text {. } \\
\text { - Mes máximo consumo: } \\
\text { o Septiembre: } 3.224 \mathrm{~m}^{3} / \mathrm{mes} \text {. } \\
\text { - Mes mínimo consumo: } \\
\text { o Febrero: } 1.917 \mathrm{~m}^{3} / \mathrm{mes} \text {. } \\
\text { - Consumo medio por plaza ofertada: } 253 \text { litros/plaza/ } \\
\text { día. } \\
\text { - Consumo medio por plaza ocupada: } 287 \text { litros/plaza/ } \\
\text { día. }\end{array}$ \\
\hline $\begin{array}{l}\text { Hoteles de } 4 \text { Estrellas } \\
\begin{array}{l}\text { - } 387 \text { plazas de media } \\
\text { - } 80 \% \text { de ocupación } \\
\text { media anual } \\
\text { - con piscina }\end{array}\end{array}$ & $\begin{array}{l}\text { - Consumo medio anual: } 40.090 \mathrm{~m}^{3} / \mathrm{año} \text {. } \\
\text { - Consumo medio mensual: } 3.340 \mathrm{~m}^{3} / \mathrm{mes} \text {. } \\
\text { - Mes máximo consumo: } \\
\text { o Septiembre: } 4.812 \mathrm{~m}^{3} / \mathrm{mes} \text {. } \\
\text { - Mes mínimo consumo: } \\
\text { o Febrero: } 2.220 \mathrm{~m}^{3} / \mathrm{mes} \text {. } \\
\text { - Consumo medio por plaza ofertada: } 289 \text { litros/plaza/ } \\
\text { día. } \\
\text { - Consumo medio por plaza ocupada: } 361 \text { litros/plaza/ } \\
\text { día. }\end{array}$ \\
\hline
\end{tabular}

Fuente: Instituto Universitario de Geografía (2004): «Estudio piloto de análisis económico del uso del agua en la industria, usos recreativos y otros usos». Ministerio de Medio Ambiente, a partir de datos de facturación facilitados por Aquagest. 


\section{Cuadro ${ }^{\circ} 6$}

EL GASTO DE AGUA POTABLE REALIZADO EN UNIDADES DE CONSUMO ASOCIADAS A LA OFERTA DE ALOJAMIENTO EXTRAHOTELERA DE BENIDORM (2001-2003)

\begin{tabular}{|c|c|}
\hline ESTABLECIMIENTO & RASGOS POR UNIDAD DE CONSUMO \\
\hline $\begin{array}{l}\text { Comunidad Propietarios } \\
\text { (poblamiento estacional) } \\
\text { - } 72 \text { viviendas } \\
\text { - Un único contador }\end{array}$ & $\begin{array}{l}\text { - Consumo medio diario: } 252 \text { litros/vivienda/día. } \\
\text { - Consumo medio mes máximo consumo: } \\
\text { o Septiembre: } 460 \text { litros/vivienda/día. } \\
\text { - Consumo medio mes mínimo consumo: } \\
\text { - Enero: } 134 \text { litros/vivienda/día. } \\
\text { - Estacionalidad del consumo (sep/enero): } 3,4\end{array}$ \\
\hline $\begin{array}{l}\text { Comunidad Propietarios } \\
\text { (poblamiento permanente) } \\
\text { - } 14 \text { viviendas } \\
\text { - Un único contador }\end{array}$ & $\begin{array}{l}\text { - Consumo medio diario: } 446 \text { litros/vivienda/día. } \\
\text { - Consumo medio mes máximo consumo: } \\
\text { o Junio: } 487 \text { litros/vivienda/día. } \\
\text { - Consumo medio mes mínimo consumo: } \\
\text { - Agosto: } 410 \text { litros/vivienda/día. } \\
\text { - Estacionalidad del consumo (junio/agosto): } 1,18\end{array}$ \\
\hline $\begin{array}{l}\text { Vivienda en bloque } \\
\text { (poblamiento estacional) } \\
\text { - Sin jardín ni piscina } \\
\text { - Contador individual }\end{array}$ & $\begin{array}{l}\text { - Consumo medio diario: } 163 \text { litros/vivienda/día. } \\
\text { - Consumo medio trimestre máximo consumo: } \\
\text { o } 3^{\circ} \text { Trimestre: } 363 \text { litros/vivienda/día. } \\
\text { - Consumo medio trimestre mínimo consumo: } \\
\circ 1^{\circ} \text { Trimestre: } 42 \text { litros/vivienda/día. } \\
\text { - Estacionalidad del consumo ( } 3^{\circ} \text { Trimestre/ } 1^{\circ} \text { Trimestre): } 8,6\end{array}$ \\
\hline $\begin{array}{l}\text { Vivienda en bloque } \\
\text { (poblamiento permanente) } \\
\text { - Sin jardín ni piscina } \\
\text { - Contador individual }\end{array}$ & $\begin{array}{l}\text { - Consumo medio diario: } 426 \text { litros/vivienda/día. } \\
\text { - Consumo medio trimestre máximo consumo: } \\
\text { ○ } 3^{\circ} \text { Trimestre: } 437 \text { litros/vivienda/día. } \\
\text { - Consumo medio trimestre mínimo consumo: } \\
\text { - } 1^{\circ} \text { Trimestre: } 404 \text { litros/vivienda/día. } \\
\text { - Estacionalidad del consumo ( } 3^{\circ} \text { Trimestre/ } 1^{\circ} \text { Trimestre): } 1,08\end{array}$ \\
\hline $\begin{array}{l}\text { Vivienda unifamiliar } \\
\text { (poblamiento estacional) } \\
\text { - Con jardín y piscina } \\
\text { - Contador individual }\end{array}$ & $\begin{array}{l}\text { - Consumo medio diario: } 865 \text { litros/vivienda/día. } \\
\text { - Consumo medio trimestre máximo consumo: } \\
\text { o } 3^{\circ} \text { Trimestre: } 2.068 \text { litros/vivienda/día. } \\
\text { - Consumo medio trimestre mínimo consumo: } \\
\text { - } 2^{\circ} \text { Trimestre: } 200 \text { litros/vivienda/día. } \\
\text { - Estacionalidad del consumo ( } 3^{\circ} \text { Trimestre } / 2^{\circ} \text { Trimestre): } 10,34\end{array}$ \\
\hline $\begin{array}{l}\text { Vivienda unifamiliar } \\
\text { (poblamiento permanente) } \\
\text { - Con jardín y piscina } \\
\text { - Contador individual }\end{array}$ & $\begin{array}{l}\text { - Consumo medio diario: } 1.257 \text { litros/vivienda/día. } \\
\text { - Consumo medio trimestre máximo consumo: } \\
\circ 3^{\circ} \text { Trimestre: } 1.585 \text { litros/vivienda/día. } \\
\text { - Consumo medio trimestre mínimo consumo: } \\
\circ 1^{\circ} \text { Trimestre: } 1.055 \text { litros/vivienda/día. } \\
\left.\text { - Estacionalidad del consumo ( } 3^{\circ} \text { Trimestre } / 1^{\circ} \text { Trimestre }\right): 1,50\end{array}$ \\
\hline $\begin{array}{l}\text { Vivienda unifamiliar } \\
\text { (poblamiento permanente) } \\
\text { - Sin jardín ni piscina } \\
\text { - Contador individual }\end{array}$ & $\begin{array}{l}\text { - Consumo medio diario: } 456 \text { litros/vivienda/día. } \\
\text { - Consumo medio trimestre máximo consumo: } \\
\text { ○ } 3^{\circ} \text { Trimestre: } 526 \text { litros/vivienda/día. } \\
\text { - Consumo medio trimestre mínimo consumo: } \\
\text { - } 1^{\circ} \text { Trimestre: } 398 \text { litros/vivienda/día. } \\
\text { - Estacionalidad del consumo ( } 3^{\circ} \text { Trimestre } / 1^{\circ} \text { Trimestre): } 1,32\end{array}$ \\
\hline
\end{tabular}

Fuente: Instituto Universitario de Geografía (2004): «Estudio piloto de análisis económico del uso del agua en la industria, usos recreativos y otros usos». Ministerio de Medio Ambiente, a partir de datos de facturación facilitados por Aquagest. 


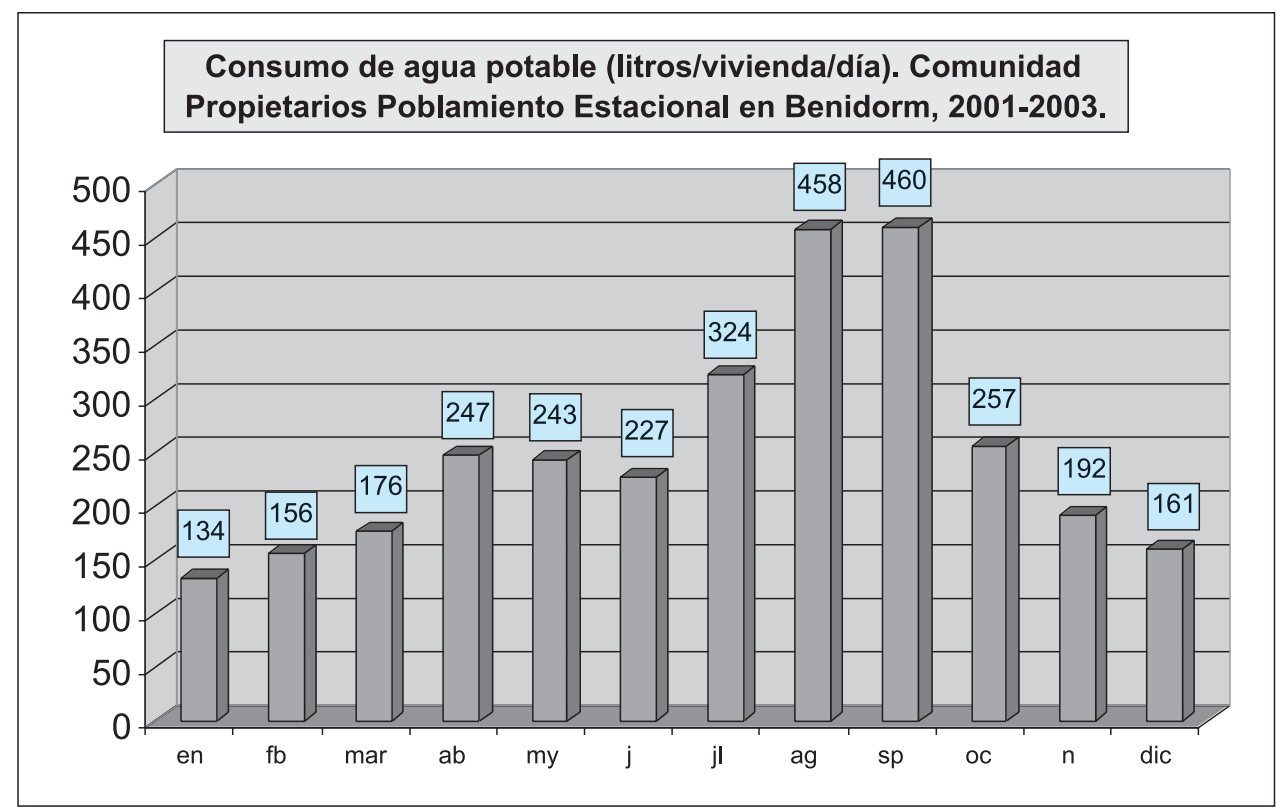

Fuente: Aquagest, 2004.

Estos datos de facturación, se refieren a comunidades de propietarios con una media de 72 viviendas, en las que pueden darse una gran diversidad de situaciones en cuanto a la composición del grupo que las ocupa y la duración de la estancia. En las comunidades de propietarios con dominio del poblamiento permanente, el consumo medio diario crece a 446 litros/vivienda/día. La estacionalidad apenas se hace perceptible $(1,18)$, con la peculiaridad de que junio (487 litros/vivienda/día) y agosto (410 litros/vivienda/día) constituyen los meses de mayor y menor consumo, respectivamente. Cabe añadir que durante los últimos años se ha impulsado la sustitución de los contadores colectivos por otros individuales por vivienda, lo que podría propiciar una reducción del consumo. Además, si los módulos de gasto por vivienda se traducen a consumo personal, tampoco resultan tan elevados como cabría esperar por el hecho de no existir contadores individuales. Así, si tenemos en cuenta un promedio de 3,5 miembros por unidad familiar o grupo alojado en este tipo de viviendas, se puede estimar que el módulo personal de gasto durante los periodos de mayor consumo se sitúa alrededor de 140 litros/habitante/día en poblamiento permanente y de 132 litros/habitante/día en estacional. Para otras modalidades de alojamiento no se ha podido disponer de datos mensuales de facturación, ya que la información facilitada se refiere a trimestres. En otro tipo de viviendas es necesario distinguir si la misma es unifamiliar o en bloque y, además, si está dotada de jardín o piscina individual. En vivienda en bloque, sin jardín ni piscina y con ocupación estacional, el consumo medio desciende a 163 litros/vivienda/día. La estacionalidad en este caso es muy acusada, con un máximo de 363 litros/vivienda/día durante el $3^{\circ}$ trimestre y de 42 litros/vivienda/día durante el $1^{\circ}$. En poblamiento permanente, este mismo tipo de vivienda alcanza un consumo medio diario de 426 litros/vivienda/día. Si se considera un promedio de 3,5 personas por vivienda, el módulo personal se situaría en 142 litros/habitante/día. La estacionalidad apenas se deja sentir, ya que el consumo del $3^{\circ}$ trimestre, con 437 litros/vivienda/día está muy cercano del efectuado durante el $1^{\circ}$ trimestre, con 404 litros/vivienda/día. 
Los mayores consumos de agua potable en los destinos turísticos de la Comunidad Valenciana se alcanzan en las viviendas de tipo unifamiliar con jardín y con piscina, tanto en poblamiento estacional como en permanente. En estacional, el consumo se eleva a 865 litros/vivienda/día, con un fuerte pico durante el $3^{\circ}$ trimestre, con 2.068 litros/vivienda/día frente a un mínimo de 200 litros/vivienda/día, durante el $2^{\circ}$ trimestre. De esta forma, la estacionalidad $\left(3^{\circ}\right.$ trimestre $/ 2^{\circ}$ trimestre) ofrece un índice de 10,34 , que supera al alcanzado en la modalidad de vivienda en bloque no permanente, con 8,6. La existencia de piscina, pero sobre todo de jardín, explica el alto consumo de agua que se efectúa durante el trimestre de verano, con 2.068 litros/vivienda/día. Con un grupo compuesto por 3,5 personas, el módulo personal de gasto se elevaría a unos 590 litros/habitante/día. El alto consumo de este tipo de viviendas se mantiene durante todo el año si se ocupa de forma permanente, con un promedio de 1.257 litros/vivienda/día. El cociente del consumo efectuado durante el trimestre de verano, con 1.585 litros/vivienda/día, y del gasto del $1^{\circ}$ trimestre, con 1.055 litros/vivienda/día, sitúa el índice de estacionalidad en 1,50. Asimismo, el módulo personal de gasto durante los meses de verano crece a 452 litros/habitante/día. La tipología de viviendas unifamiliares sin jardín ni piscina, dentro de la modalidad de poblamiento permanente, ha conocido también durante la última década una fuerte expansión en territorio valenciano. En este caso, el promedio anual de agua facturada asciende a 456 litros/vivienda/día, con mínimo en el $1^{\circ}$ trimestre (398 litros/vivienda/día) y máximo en el $3^{\circ}$ trimestre (526 litros/vivienda/día). En consecuencia, con un valor de 1,32, la estacionalidad no se hace patente de forma tan acusada como ocurre con las viviendas unifamiliares con jardín y con piscina. A su vez, se puede estimar un módulo personal de 152 litros/habitante/día, que lo aleja de los 457 litros/habitante/día que se alcanzan en unifamiliar con jardín y piscina, con poblamiento permanente.

Aunque el alojamiento hotelero y extrahotelero resulta determinante en el consumo agua, la actividad turística puede propiciar el desarrollo de otras modalidades de alojamiento y, por otra parte, de oferta complementaria relacionado con el ocio y los servicios. En camping, Benidorm disponía en 2002 de una oferta de 10 establecimientos, con 7.673 plazas, que se distribuían en 2.892 plazas de $1^{\text {a }}$ categoría y 4.781 plazas de $2^{\text {a }}$ categoría. Se ha accedido a los datos de facturación de 2001 a 2003 de un camping de $1^{\text {a }}$ categoría, que permanece abierto durante todo el año, con una oferta de 487 plazas y una extensión de $7.000 \mathrm{~m}^{2}$. Es de notar, que este tipo de camping suele ofertar a sus clientes piscina, lavandería, supermercado, enfermería y otro tipo de servicios. El consumo medio del citado camping de 487 plazas y de $1^{\text {a }}$ categoría asciende a $15.069 \mathrm{~m}^{3} /$ año. A tenor de los datos de consumo mensual, se puede establecer que la mayor actividad de este tipo de establecimientos se produce en enero y febrero, con 128 litros/plaza ofertada/día y 120 litros/plaza ofertada/día respectivamente. En cambio, al contrario de lo que ocurre con los establecimientos típicos de la oferta hotelera y extrahotelera, el menor consumo de agua potable se produce durante los meses de julio y agosto, con 60 y 66 litros/plaza ofertada/día, respectivamente. Durante los meses centrales del invierno es frecuente la afluencia de turistas extranjeros, muchos de ellos con autocaravana, que pueden acceder a todo tipo de comodidades y servicios a costes medios de 12 euros por plaza ocupada. Este hecho otorga cierto tipo de ventajas competitivas frente a los establecimientos hoteleros cuando se trata de estancias superiores a las 2 semanas.

Otro rasgo característico de los destinos turísticos con fuerte dinamismo social y económico, es la existencia de una abundante oferta complementaria relacionado con el ocio y los servicios. Por ejemplo, el municipio de Benidorm cuenta con un gran número de bares, cafeterías y restaurantes. Tan sólo en restaurantes, este municipio disponían en 2002 de una oferta de 331 establecimientos con 20.653 plazas. El consumo medio de un 
restaurante se eleva a 5.200 litros/día, con pico en septiembre (7.000 litros/día) y mínimo en marzo (2.400 litros/día), coincidiendo, respectivamente, con los periodos de mayor y menor actividad turística. Ocurre igual con otros establecimientos, como las lavanderías, que consumen una media de 6.000 litros/día, con máximo en septiembre (7.600 litros/día) y mínimo en enero (4.400 litros/día). El gasto de agua crece a 17.000 litros/día, cuando se trata de una gasolinera dotada con un lavadero de coches, donde se hace también patente la estacionalidad de la actividad, ya que el consumo medio de agosto (26.000 litros/día) casi triplica al efectuado durante el mes de enero (9.000 litros/día).

\section{Cuadro $\mathrm{n}^{\circ} 7$}

EL GASTO DE AGUA POTABLE REALIZADO EN UNIDADES DE CONSUMO ASOCIADAS AL OCIO Y LOS SERVICIOS EN BENIDORM (2001-2003)

\begin{tabular}{|c|c|}
\hline ESTABLECIMIENTO & RASGOS POR UNIDAD DE CONSUMO \\
\hline Restaurante & $\begin{array}{l}\text { - Consumo medio diario: } 5.200 \text { litros/día. } \\
\text { - Consumo medio mes máximo consumo: } \\
\text { o Septiembre: } 7.700 \text { litros/día. } \\
\text { - Consumo medio mes mínimo consumo: } \\
\text { - Marzo: } 2.400 \text { litros/día. } \\
\text { - Estacionalidad del consumo (sep/mar): 3,2 }\end{array}$ \\
\hline Lavandería & $\begin{array}{l}\text { - Consumo medio diario: } 6.000 \text { litros/día. } \\
\text { - Consumo medio mes máximo consumo: } \\
\text { o Septiembre: } 7.600 \text { litros/día. } \\
\text { - Consumo medio mes mínimo consumo: } \\
\text { - Enero: } 4.400 \text { litros/vivienda/día. } \\
\text { - Estacionalidad del consumo (junio/agosto): } 1,72\end{array}$ \\
\hline $\begin{array}{l}\text { Gasolinera con lavadero } \\
\text { de coches. }\end{array}$ & $\begin{array}{l}\text { - Consumo medio diario: } 17.000 \text { litros/día. } \\
\text { - Consumo medio mes máximo consumo: } \\
\text { o Agosto: } 26.000 \text { litros/día. } \\
\text { - Consumo medio mes mínimo consumo: } \\
\text { - Enero: } 9.000 \text { litros/día. } \\
\text { - Estacionalidad del consumo (Agosto/Enero): 2,88 }\end{array}$ \\
\hline
\end{tabular}

Fuente: Instituto Universitario de Geografía (2004): «Estudio piloto de análisis económico del uso del agua en la industria, usos recreativos y otros usos». Ministerio de Medio Ambiente, a partir de datos de facturación facilitados por Aquagest.

En consecuencia, se puede afirmar que en el caso de Benidorm y de otros destinos turísticos de la Comunidad Valenciana, se está ante unos usos turísticos que ofrecen una gran diversidad en su comportamiento, con módulos personales que pueden variar desde los 140 litros/habitante/día a los 600 litros, dependiendo del tipo de alojamiento. No obstante, conviene subrayar que se tarta de usos con unas fuertes implicaciones económicas y sociales, con un consumo global exiguo en relación con otras demandas como las agrarias. El mayor inconveniente que plantean los usos urbano-turísticos es la estacionalidad, debido al tipo de oferta de alojamiento dominante en núcleos de veraneo como Santa Pola, la misma Benidorm, Denia, Calpe, por citar los destinos más importantes de la provincia de 
Alicante; Cullera, Gandía, Sueca, Sagunto, la Pobla de Farnals, y Oliva en la de Valencia; Benicasim, Peñíscola, Alcalá de Chivert, Benicarló y Vinaroz en Castellón. Las soluciones para evitar problemas de suministro como los padecidos ocasionalmente por algunos de estos municipios por efecto de la estacionalidad, pasan necesariamente por la tecnificación de los sistemas de gestión en baja y por sobredimensionar las infraestructuras de captación, distribución, saneamiento y depuración, otorgando si acaso una mayor participación a las fuentes no convencionales y a los bancos públicos del agua. De otro lado, estas actuaciones deben acompañarse de políticas dirigidas a promover cambios estructurales que incorporen iniciativas empresariales, de recualificación del producto turístico y de introducción de líneas de oferta dinámicas que, al fin y al cabo, son las que permiten extraer una máxima eficiencia social y económica a este tipo de usos del agua (Vera Rebollo, J.F. e Ivars Baidal, J. 2002).

\section{BIBLIOGRAFÍA}

AEAS (2004): Suministro de agua potable y saneamiento en España (2004). Asociación Española de Abastecimientos de Agua y Saneamiento, Madrid, 143 p.

BBVA (2000): Renta Nacional de España y su distribución provincial. Año 1995 y avances 19961999. Fundación BBVA, Bilbao, 546 p.

BLANQUER CRIADO, D. (2002): «Turismo residencial y urbanizaciones privadas: los servicios públicos de prestación obligatoria y alternativas a su incumplimiento por el ayuntamiento». En Ordenación y gestión del territorio turístico, Fundación Cañada Blanch, Ed. Tirant lo Blanch, Valencia, pp. 840-950.

CALVO GARCÍA-TORNEL, F. (1999): «Caudales propios y foráneos en una cuenca exangüe: La del Segura». En Los usos del Agua en España, Instituto Universitario de Geografía, Universidad de Alicante, Caja de Ahorros del Mediterráneo, pp. 485-508.

CONSELLERÍA DE TURISME (2006): El turismo en la Comunidad Valenciana, 2006. Generalidad Valenciana, $92 \mathrm{p}$.

DOMENE GÓMEZ, E. Y SAURÍ PUJOL, D. (2003): «Modelos urbanos y consumo de agua. El riego de jardines privados en la región metropolitana de Barcelona». En Investigaciones Geográficas, $\mathrm{n}^{\mathrm{o}}$ 32, Instituto Universitario de Geografía, Universidad de Alicante, Alicante, pp. 5-17.

FERNÁNDEZ-MONTES LLORD, C., TORREGROSA MARTÍ, T. Y GONZÁLEZ LÓPEZ, A. (2003): Demanda hídrica consolidada y evolución esperada. Abastecimientos e industria. COEPA, Alicante, Informe Policopiado.

FRONTANA GONZÁLEZ, J. (2002): Agua y Territorio. Recursos y conflictos de usos en Andalucía y en la costa de Granada. Instituto de Desarrollo Regional, Universidad de Granada, 385 p.

GIL OLCINA, A. (1995): «Conflictos autonómicos sobre trasvases de agua en España». En Investigaciones Geográficas, ${ }^{\circ}$ 13, Instituto Universitario de Geografía, Universidad de Alicante, Alicante, pp. 17-28.

GIL OLCINA, A. Y RICO AMORÓS, A.M. (2001): «Demanda y disponibilidad de agua». En Geografía de España, Edit. Ariel, Barcelona, pp. 441-454.

GIL OLCINA, A. (2002): «De los Planes Hidráulicos a la Planificación Hidrológica». En Insuficiencias hídricas y Plan Hidrológico Nacional, Instituto Universitario de Geografía, Universidad de Alicante, Caja de Ahorros del Mediterráneo, pp. 11-44.

HERNÁNDEZ HERNÁNDEZ, M. (2006): «Análisis de la dinámica turística y su incidencia en el consumo de agua en los Grupos de Acción Local de la Comunidad Valenciana». En Investigaciones Geográficas, $\mathrm{n}^{\circ}$ 40, Instituto Universitario de Geografía, Universidad de Alicante, Alicante, pp. 97-118.

IRIBAS SÁNCHEZ, J.M. (1995): «Consideraciones sobre la situación urbana y turística del litoral alicantino». En Agua y Espacios de Ocio, Universidad Internacional Menéndez Pelayo, Fundación CAM, Alicante, pp. 61-90. 
IVARS BAIDAL, J. (2001): «Planificación y gestión del desarrollo turístico sostenible: propuestas para la creación de un sistema de indicadores». En Documentos de Trabajo, Instituto Universitario de Geografía, Universidad de Alicante, $72 \mathrm{p}$.

JUÁREZ SÁNCHEZ-RUBIO, C. (2000): «El papel de la oferta de agua en el desarrollo productivo de la Vega Baja del Segura (Alicante)». En Alquibla, Revista de Investigación del Bajo Segura, $\mathrm{n}^{\circ}$ 6, pp. 99-118.

JUÁREZ SÁNCHEZ-RUBIO, C. (2004): «Sistemas de indicadores de sostenibilidad y desarrollo turístico. Aplicación a la comarca del Bajo Segura». En Investigaciones Geográficas, no 33, Instituto Universitario de Geografía, Universidad de Alicante, Alicante, pp. 17-37.

JUÁREZ SÁNCHEZ-RUBIO, C. (2007): «Indicadores hídricos de sostenibilidad y desarrollo turístico y residencial en la Costa Blanca». En Boletín de la Asociación de Geógrafos Españoles, (en prensa).

MARTÍN MARTÍN V. Y RODRÍGUEZ BRITO, W. (1999): «Conflictos de los usos del agua en Canarias». En Los Usos del Agua en España, Instituto Universitario de Geografía, Universidad de Alicante, Caja de Ahorros del Mediterráneo, pp. 645-681.

MELGAREJO MORENO, J. (2000): «Balance económico del trasvase Tajo-Segura». En Investigaciones Geográficas, $n^{\circ}$ 24. Instituto Universitario de Geografía, Universidad de Alicante, Alicante, pp. 69-95.

MORALES GIL, A. Y VERA REBOLLO, J.F. (1989): La Mancomunidad de los Canales del Taibilla. Instituto Universitario de Geografía de la Universidad de Alicante-Academia Alfonso X El Sabio. Madrid, 133 p.

MORALES GIL, A. (2001): Agua y Territorio en la Región de Murcia. Fundación Centro de Estudios Históricos e Investigaciones Locales, Colección Realidades, Murcia, 270 p.

NAVALÓN GARCÍA, R. (2001): Agricultura y turismo en la franja costera de la Comunidad Valenciana. Edit. Fundació Bancaixa, Colección Economía y Empresa, Valencia, 599 p.

OLCINA CANTOS, J. (2002): «Planificación hidrológica y recursos de agua no convencionales en España». En Insuficiencia Hídrica y Plan Hidrológico Nacional, Instituto Universitario de Geografía, Universidad de Alicante, Caja de Ahorros del Mediterráneo, pp. 69-130.

PRATS RICO, D. Y MELGAREJO MORENO, J. (2006): Desalación y reutilización de aguas. Situación en la provincia de Alicante. Fundación Coepa, Alicante, 164 p.

QUEREDA SALA, J. MONTÓN CHIVA, E. Y ESCRIG BARBERÁ, J. (2002): «El déficit hídrico y las necesidades de transferencias foráneas en la provincia de Castellón». En Insuficiencias Hídricas y Plan Hidrológico Nacional, Instituto Universitario de Geografía, Universidad de Alicante, Caja de Ahorros del Mediterráneo, pp. 347-371.

RICO AMORÓS, A.M. (1998): Agua y desarrollo en la Comunidad Valenciana. Universidad de Alicante, $163 \mathrm{p}$.

RICO AMORÓS, A.M., OLCINA CANTOS, J., PAÑOS CALLADO, V. Y BAÑOS CASTIÑEIRA, C. (1998): Depuración, desalación y reutilización de aguas en España. Edit. Oikos-Tau, Barcelona, $255 \mathrm{p}$.

RICO AMORÓS, A.M. (2001): «Actuaciones frente a las sequías en España». En Causas y consecuencias de las sequías en España, Instituto Universitario de Geografía, Universidad de Alicante, Caja de Ahorros del Mediterráneo, pp. 421-486.

RICO AMORÓS, A.M. (2004): «Sequías y abastecimientos de agua potable en España». En Boletín de la Asociación de Geógrafos Españoles, n 37, Murcia, pp. 137-181.

ROGER FERNÁNDEZ, G. (2002): «El urbanismo y la ordenación y gestión del territorio turístico». En Ordenación y gestión del territorio turístico, Fundación Cañada Blanch, Ed. Tirant lo Blanch, Valencia, pp. 49-77.

SAURÍ, D., OLCINA, J. y RICO, A. (2007). «The March towards Privatisation? Urban Water Supply and Sanitation in Spain». In Journal of Comparative Social Welfare, Volume 23, Issue 2, Routledge, pp. 131-139.

TORRES ALFOSEA, F.J. (2001): «El litoral de la Comunidad Valenciana». En La Periferia Emergente, Editorial Ariel, Barcelona, pp. 515-537.

VERA REBOLLO, J.F. Y RICO AMORÓS, A.M. (1995): «Los sistemas de abastecimiento de agua potable en un espacio turístico y residencial: la Costa Blanca». En Cuatro siglos de técnica 
hidráulica en tierras Alicantinas, Alberola Romá, A. (Ed.), Instituto de Cultura Juan Gil-Albert, Diputación Provincial de Alicante, pp. 43-66.

VERA REBOLLO, J.F. Y BAÑOS CASTIÑEIRA, C. (2001): «Actividad y espacios turísticos». En La Periferia Emergente, Editorial Ariel, Barcelona, pp. 373-395.

VERA REBOLLO, J.F. (2002): «Transferencia de recursos y demandas turísticas» En Insuficiencias Hídricas y Plan Hidrológico Nacional (Gil Olcina, A. y Morales Gil A. eds.), CAM e Instituto Universitario de Geografía, Universidad de Alicante, Alicante, pp. 179-200.

VERA REBOLLO, J.F. E IVARS BAIDAL, J.A. (2002): «Turismo, territorio y desarrollo regional en la Comunidad Valenciana». En Ordenación y gestión del territorio turístico, Fundación Cañada Blanch, Ed. Tirant lo Blanch, Valencia, pp. 152-189.

VERA REBOLLO, J.F.,CASADO DÍAZ, J.Mª Y RAMÓN RODRÍGUEZ, A.B. (2004): «Consideraciones sobre el impacto del Plan Hidrológico Nacional en el sector turístico de la provincia de Alicante», en MELGAREJO MORENO, J. (ed.). Repercusiones socioeconómicas del Plan Hidrológico Nacional en la provincia de Alicante. Alicante: Fundación COEPA, pp. 205-267.

VERA REBOLLO, J.F. (2006): «Agua y modelo de desarrollo turístico: la necesidad de nuevos criterios para la gestión de los recursos». En Boletín de la Asociación de Geógrafos Españoles, $\mathrm{n}^{\mathrm{o}}$ 42, Murcia, pp. 155-178. 